\title{
Calmodulin Bidirectionally Regulates Evoked and Spontaneous Neurotransmitter Release at Retinal Ribbon Synapses
}

\author{
Chao-Qun Liang, ${ }^{1, *}$ Gong Zhang, ${ }^{1, *}$ Lei Zhang, ${ }^{2}$ Si-Yun Chen, ${ }^{1}$ Jun-Nan Wang, ${ }^{1}$ Ting-Ting Zhang, ${ }^{1}$ \\ Joshua H. Singer, ${ }^{2}$ and $\mathbb{D}^{\text {Jiang-Bin } \mathrm{Ke}^{1}}$
}

https://doi.org/10.1523/ENEURO.0257-20.2020

${ }^{1}$ State Key Laboratory of Ophthalmology, Zhongshan Ophthalmic Center, Sun Yat-sen University, Guangzhou 510060, China and ${ }^{2}$ Department of Biology, University of Maryland, College Park, MD 20742

\begin{abstract}
For decades, a role for the $\mathrm{Ca}^{2+}$-binding protein calmodulin (CaM) in $\mathrm{Ca}^{2+}$-dependent presynaptic modulation of synaptic transmission has been recognized. Here, we investigated the influence of CaM on evoked and spontaneous neurotransmission at rod bipolar $(\mathrm{RB})$ cell $\rightarrow$ All amacrine cell synapses in the mouse retina. Our work was motivated by the observations that expression of $\mathrm{CaM}$ in RB axon terminals is extremely high and that $\left[\mathrm{Ca}^{2+}\right]$ in RB terminals normally rises sufficiently to saturate endogenous buffers, making tonic CaM activation likely. Taking advantage of a model in which RBs can be stimulated by expressed channelrhodopsin-2 (ChR2) to avoid dialysis of the presynaptic terminal, we found that inhibition of CaM dramatically decreased evoked release by inhibition of presynaptic $\mathrm{Ca}$ channels while at the same time potentiating both $\mathrm{Ca}^{2+}$-dependent and $\mathrm{Ca}^{2+}$-independent spontaneous release. Remarkably, inhibition of myosin light chain kinase (MLCK), but not other CaM-dependent targets, mimicked the effects of CaM inhibition on evoked and spontaneous release. Importantly, initial antagonism of CaM occluded the effect of subsequent inhibition of MLCK on spontaneous release. We conclude that CaM, by acting through MLCK, bidirectionally regulates evoked and spontaneous release at retinal ribbon synapses.
\end{abstract}

Key words: All amacrine cell; calmodulin; myosin light chain kinase; neurotransmitter release; retinal rod bipolar cell; ribbon synapse

\section{Significance Statement}

Calmodulin (CaM), a $\mathrm{Ca}^{2+}$-binding protein expressed throughout the CNS, functions as a presynaptic modulator of synaptic transmission. We showed that CaM was strongly expressed in the axon terminals of rod bipolar (RB) cells of the mouse retina. Inhibition of CaM decreased evoked release while potentiating spontaneous release at $\mathrm{RB} \rightarrow \mathrm{All}$ amacrine cell synapses; this effect was mimicked by inhibition of myosin light chain kinase (MLCK), a CaM target. Thus, we conclude that CaM, acting through MLCK, bidirectionally regulates evoked and spontaneous release at retinal ribbon synapses.

\section{Introduction}

At chemical synapses, fast, synchronous neurotransmitter release is evoked when membrane depolarization, usually in the form of action potentials, arrives at presynaptic axon terminals and opens voltage-gated calcium

Received June 12, 2020; accepted November 21, 2020; First published December 8, 2020.

The authors declare no competing financial interests. channels (VGCCs), permitting $\mathrm{Ca}^{2+}$ influx to trigger fusion of synaptic vesicles. Spontaneous neurotransmitter release also occurs independent from presynaptic activity, and understanding of its separate roles in synapse formation, synaptic maintenance and dendritic protein translation is

Author contributions: J.H.S. and J.-B.K. designed research; C.-Q.L., G.Z., L.Z., S.-Y.C., J.-N.W., T.-T.Z., and J.-B.K. performed research; C.-Q.L., G.Z., L.Z., J.H.S., and J.-B.K. analyzed data; J.H.S. and J.-B.K. wrote the paper. 
emerging (Kavalali, 2015; Andreae and Burrone, 2018; Chanaday and Kavalali, 2018). Recent studies support the notion that there are distinct molecular mechanisms underlying evoked and spontaneous release: these two forms of neurotransmission may originate from separate synaptic vesicle pools (Chanaday and Kavalali, 2018), although evidence against this hypothesis also exists (Groemer and Klingauf, 2007; Hua et al., 2010; Wilhelm et al., 2010; Schneggenburger and Rosenmund, 2015).

Proteins such as Vti1a, VAMP7, Doc2 and copine-6 selectively regulate spontaneous release (Groffen et al., 2010; Pang et al., 2011; Ramirez et al., 2012; Bal et al., 2013; Liu et al., 2018), whereas others, e.g., RIM1 and RIM-binding proteins (RBPs), are essential for evoked but not spontaneous release (Calakos et al., 2004; Acuna et al., 2015; Robinson et al., 2019). Synaptotagmin-1 and complexins appear to promote evoked release but suppress spontaneous release (Maximov and Südhof, 2005; Huntwork and Littleton, 2007; Xu et al., 2009; Yang et al., 2013; Bai et al., 2016; Mortensen et al., 2016), although a more recent study argues against the role of complexins as "fusion clamps" for spontaneous release, and shows that knock-out of complexins reduces both spontaneous and evoked release (López-Murcia et al., 2019). Finally, neuromodulation can affect spontaneous and evoked release differentially: in L5 pyramidal cells of mouse brains, presynaptic NMDA receptors regulate evoked and spontaneous release via nonoverlapping RIM1-dependent and JNK2-dependent mechanisms, respectively (Abrahamsson et al., 2017).

Because they are designed to signal tonically over extended periods (Matthews and Fuchs, 2010; Cho and von Gersdorff, 2012), ribbon-type excitatory synapses experience sustained $\mathrm{Ca}^{2+}$ influx and elevations in intracellular $\left[\mathrm{Ca}^{2+}\right]$ and appear to be a good model for understanding modulation of evoked and spontaneous release. Imaging of fish bipolar cells and salamander rod photoreceptors show that evoked release is concentrated near ribbontype active zones (AZs) and spontaneous release occurs at a higher rate away from ribbon sites (Midorikawa et al., 2007; Zenisek, 2008; Chen et al., 2013), and electrophysiological analysis of transmission at mouse rod bipolar $(\mathrm{RB}) \rightarrow$ All synapses reveals two putatively separate pools of synaptic vesicles: ribbon-associated and ribbon independent (Mehta et al., 2014). Deletion of RIBEYE, a ribbon AZ-specific protein, results in an absence of ribbon AZs, as expected, and severely impairs evoked, but not spontaneous, release at $\mathrm{RB} \rightarrow$ All synapses (Maxeiner et al., 2016).

This work was supported by the National Institutes of Health Grant EY017836 (to J.H.S.) and by the Fundamental Research Funds of State Key Laboratory of Ophthalmology, Sun Yat-sen University (J.-B.K.).

${ }^{*} \mathrm{C}$.-Q.L. and G.Z. contributed equally to this work.

Correspondence should be addressed to Joshua H. Singer at jhsinger@ umd.edu or Jiang-Bin Ke at kejiangbin@mail.sysu.edu.cn.

https://doi.org/10.1523/ENEURO.0257-20.2020 Copyright $(0) 2021$ Liang et al.

This is an open-access article distributed under the terms of the Creative Commons Attribution 4.0 International license, which permits unrestricted use, distribution and reproduction in any medium provided that the original work is properly attributed.
Here, we used the $\mathrm{RB} \rightarrow$ All synapse in the mouse retina, a well-established model ribbon-type synapse (Singer, 2007; Singer et al., 2009; Pangrsic et al., 2018), to examine a role for calmodulin $(\mathrm{CaM})$ in the regulation of evoked and spontaneous transmission at synapses that experience tonic elevations in $\left[\mathrm{Ca}^{2+}\right]$ and release neurotransmitter in a sustained manner over long periods.

$\mathrm{CaM}, \mathrm{C} \mathrm{Ca}^{2+}$-binding protein highly conserved among eukaryotes and expressed ubiquitously and abundantly in the brain, including the retina (Pochet et al., 1991), interacts with a large number of presynaptic targets, including, but not limited to, $\mathrm{Ca}^{2+} / \mathrm{CaM}$-dependent kinase II (CaMKII), myosin light chain kinase (MLCK), calcineurin, Munc13, and $\mathrm{Ca}$ channels, all of which are involved in multiple mechanisms regulating the vesicle cycle (Hoeflich and Ikura, 2002; Ben-Johny and Yue, 2014; Chanaday and Kavalali, 2018; Tarasova et al., 2018). We used a variety of experimental approaches to demonstrate that CaM, by acting through MLCK, bidirectionally regulates evoked and spontaneous release at retinal ribbon-type synapses.

\section{Materials and Methods}

\section{Animals}

All animal procedures were performed in accordance with the University of Maryland and Sun Yat-sen University animal care committees' regulations. Four transgenic mouse lines, two cre driver lines and two reporter lines, were used. RBs were targeted for transgene expression in the Pcp2-cre $[\mathrm{Tg}(\mathrm{Pcp} 2-\mathrm{cre}) 1 \mathrm{Amc} / \mathrm{J}$; Jax 006207] and BAC-Pcp2-IRES-Cre [B6.Cg-Tg(Pcp2-cre) 3555Jdhu/J; Jax 010536] lines, both of which express cre recombinase primarily in RBs under the control of mouse Purkinje cell protein (Pcp2; Zhang et al., 2005; Ivanova et al., 2010). Channelrhodopsin-2 (ChR2) or GCaMP3 were expressed in RBs by cre-dependent recombination after crossing a cre driver line with either Ai32 [B6.Cg-Gt

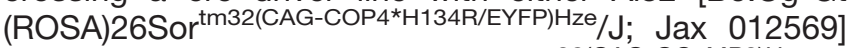

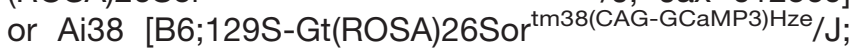
Jax 014538] lines, respectively (Madisen et al., 2012; Zariwala et al., 2012). The wild-type (wt) C57BL/6J, Pcp2-cre::Ai32 and Pcp2-cre::Ai38 mice of either sex at ages between 4 and 20 weeks were used in this study.

\section{Electrophysiology}

Retinal slices (200- $\mu \mathrm{m}$ thickness) were prepared from light-adapted retina isolated from either Pcp2-cre::Ai32 or wt mice. A retina was isolated into sodium bicarbonate buffered Ames' medium (Sigma) equilibrated with 95\% $\mathrm{O}_{2}$ and $5 \% \mathrm{CO}_{2}$ (carbogen) at room temperature. For slice preparation, the retina was embedded in low-melting temperature agarose (Sigma Type VIIA, 2-3\% in a HEPES-buffered saline), and slices were cut on a vibrating microtome (Leica VT1200s). Slices were stored in carbogen-bubbled Ames' medium at room temperature until use.

Recordings were performed at near-physiological temperature $\left(30-35^{\circ} \mathrm{C}\right)$. Retinal slices were continuously superfused at a rate of $1-2 \mathrm{ml} / \mathrm{min}$ with carbogen-bubbled 
artificial CSF (ACSF) containing the following: $119 \mathrm{~mm} \mathrm{NaCl}$, $23 \mathrm{~mm} \mathrm{NaHCO}$, $10 \mathrm{~mm}$ glucose, $1.25 \mathrm{~mm} \mathrm{NaH}_{2} \mathrm{PO}_{4}, 2.5 \mathrm{~mm}$ $\mathrm{KCl}, 1.15 \mathrm{~mm} \mathrm{CaCl}_{2}, 1.5 \mathrm{~mm} \mathrm{MgCl}$, $2 \mathrm{~mm}$ NaLactate, and 2 mм NaPyruvate. Picrotoxin (50 $\mu \mathrm{M}),(1,2,5,6$-tetrahydropyridin-4-yl) methylphosphinic acid (TPMPA, $50 \mu \mathrm{M}$ ) or 4-imidazoleacetic acid (I4AA, $10 \mu \mathrm{M})$, strychnine $(0.5 \mu \mathrm{M})$, tetrodotoxin (TTX; $0.5 \mu \mathrm{M}$ ), 2-amino-4-phosphonobutyate (L-AP4, $2 \mu \mathrm{M})$, and (S)-1-(2-amino-2-carboxyethyl)-3(2-carboxy-5-phenylthiophene-3-yl-methyl)-5-methylpyrimidine-2,4-dione (ACET, $1 \mu \mathrm{M}$ ) were added to the ACSF to block $\mathrm{GABA}_{\mathrm{A}} \mathrm{R}$-mediated, GABA $\mathrm{C}$-mediated, GlyR-mediated, voltage-gated $\mathrm{Na}$ channel-mediated, mGluR6-regulated channel-mediated, and kainate receptor-mediated currents, respectively.

During current-clamp recordings, pipettes were filled with the following: $110 \mathrm{~mm}$ K-gluconate, $5 \mathrm{~mm} \mathrm{NaCl}, 10$ mM HEPES, $8 \mathrm{~mm}$ Tris-phosphocreatine, $4 \mathrm{~mm}$ Mg-ATP, $0.4 \mathrm{~mm} \mathrm{Na}-\mathrm{GTP}$, and $1 \mathrm{~mm}$ BAPTA. The $\mathrm{pH}$ value was adjusted to 7.2 with $\mathrm{KOH}$ and osmolarity to $\sim 285 \mathrm{mOsm}$ with sucrose. During voltage-clamp recordings, pipettes were filled with the following: $95 \mathrm{~mm}$ Cs-methanesulfonate, $20 \mathrm{~mm}$ TEA-Cl, $1 \mathrm{~mm}$ 4-AP, $10 \mathrm{~mm}$ HEPES, $8 \mathrm{~mm}$ Tris-phosphocreatine, $4 \mathrm{~mm}$ Mg-ATP, $0.4 \mathrm{~mm} \mathrm{Na}-\mathrm{GTP}$, and $1 \mathrm{~mm}$ BAPTA. The $\mathrm{pH}$ value was adjusted to 7.2 with $\mathrm{CsOH}$ and osmolarity to $2285 \mathrm{mOsm}$ with sucrose. Alexa Fluor 594 or 647 was included in the pipette solutions to visualize the cell morphology after recordings. Generally, RB holding potential was $-60 \mathrm{mV}$ and All holding potential was $-80 \mathrm{mV}$, and membrane potentials were corrected for junction potentials of $\sim-10 \mathrm{mV}$. Access resistances were $<25 \mathrm{M} \Omega$ for RBs and $<20 \mathrm{M} \Omega$ for All amacrine cells and were compensated by 50$90 \%$. Recordings were made using MultiClamp $700 \mathrm{~B}$ amplifiers. Recorded currents were digitized at 10$20 \mathrm{kHz}$ and low-pass filtered at $2 \mathrm{kHz}$ by an ITC-18 A/D board (Heka/Instrutech) controlled by software written in Igor Pro 6 (WaveMetrics). Recorded RB Ca currents were leak-subtracted off-line ( $\mathrm{P} / 4$ protocol). Analysis was performed in Igor Pro.

\section{Optogenetics}

ChR2 was activated by a high-power blue LED (Thor Laboratories; $\lambda_{\text {peak }} 470 \mathrm{~nm}$ ) directed through the $60 \times$ or $100 \times$ lenses to create a light spot (125 or $75 \mu \mathrm{m}$ in diameter, respectively). The light intensities and durations were controlled by software written in Igor Pro.

\section{Calcium imaging}

Retinal slices (200- $\mu \mathrm{m}$ thickness) were prepared, as described above, from light-adapted retina isolated from Pcp2-cre::Ai38 mice. Imaging of GCaMP3 signals was performed using two-photon laser-scanning microscopy (2PLSM). GCaMP3 was excited using a pulsed infrared laser (Chameleon; Coherent) tuned to a 910-nm excitation wavelength, and emitted light was passed through a series of dichroic mirrors and filters and collected by GaAsP photomultiplier tubes (Thor Laboratories). Frames containing multiple RB axon terminals in each of which several varicosities were evident were collected at $\sim 19 \mathrm{~Hz}$ and every nine frames were averaged to generate each calcium imaging picture shown below. Collected data were analyzed using ImageJ (Schneider et al., 2012).

\section{Immunohistochemistry}

Retinas from wt mice were dissected and fixed in 4\% PFA for $20 \mathrm{~min}$. After fixation, retinas were infiltrated with graded $(10 \%, 20 \%$, and $30 \%)$ sucrose in PB and sectioned vertically at $14 \mu \mathrm{m}$ on a cryostat (Leica). Immunohistochemical labeling was conducted by using the indirect fluorescence method. Retinal sections were blocked in $1 \%$ bovine serum albumin (BSA) in $0.1 \%$ Triton X-100 in PBS (PBST) for $2 \mathrm{~h}$. Following removal of the blocking solutions, retinal sections were incubated with primary antibodies overnight at $4^{\circ} \mathrm{C}$. The following primary antibodies were used: rabbit antiCaM (1:500, \#301003, Synaptic Systems), mouse anti-PKC $\alpha$ (1:200, \#P5704, Sigma), and mouse anti-CtBP2 (1:500, \#612004, BD Biosciences). After rinsing, corresponding secondary antibodies including Alexa Fluor 488 donkey anti-rabbit (1:200, \#A21206, Thermo Fisher Scientific) and Alexa Fluor 568 donkey anti-mouse (1:200, \#A10037, Thermo Fisher Scientific) were applied for $2 \mathrm{~h}$ in darkness. All antibodies were diluted with $5 \%$ BSA in PBST. After rinsing, DAPI stain (1:1000, \#C1002, Beyotime) was applied for $10 \mathrm{~min}$ at room temperature. Between incubations, sections were washed three times for 5 min each using PBST. Control experiments were conducted either by preincubation of the anti-CaM antibody with the CaM or $\mathrm{Ca}^{2+}$-binding protein 5 (CaBP5) immunopeptides (EEFVQMMTAK corresponding to AA 140-149 in rat/mouse CaM, \#301-OP, Synaptic Systems; EEFVKMMSR corresponding to AA 165-173 in mouse CaBP5, synthesized by Sangon Biotech) or by omission of both primary antibodies. All labeled sections were examined with a confocal laser scanning microscope (LSM 880, Carl Zeiss) with Plan-Apochromat $63 \times / 1.4$ or $100 \times / 1.40$ oil-immersion objectives. Images were adjusted for contrast and brightness by using ZEN software (Carl Zeiss) or Photoshop software (Adobe Systems).

\section{Chemicals}

ACET, picrotoxin, TPMPA, strychnine, DNQX, W-7, calmidazolium (CMZ), CALP1, ML-9, KN-62, MMPX, ascomycin, BAPTA-AM, thapsigargin (Tg), YM-58483 were obtained from Tocris. L-AP4 was purchased from Tocris or Cayman. Meclofenamic acid (MFA) and I4AA were obtained from Sigma. TTX was purchased from Alomone Labs. Drugs were dissolved in dimethylsulfoxide (DMSO) where appropriate and then diluted into the bath solution. The final concentrations of DMSO were $<0.1 \%(\mathrm{v} / \mathrm{v})$ in all experiments.

\section{Statistical analysis}

Statistical analysis was performed with Prism 6 (GraphPad software). For better comparison among different groups, data acquired in each cell were normalized to the value under control condition. The KolmogorovSmirnov (KS) test was used to compare the cumulative distributions of data. Differences between experimental samples were assessed for significance using two-tailed 

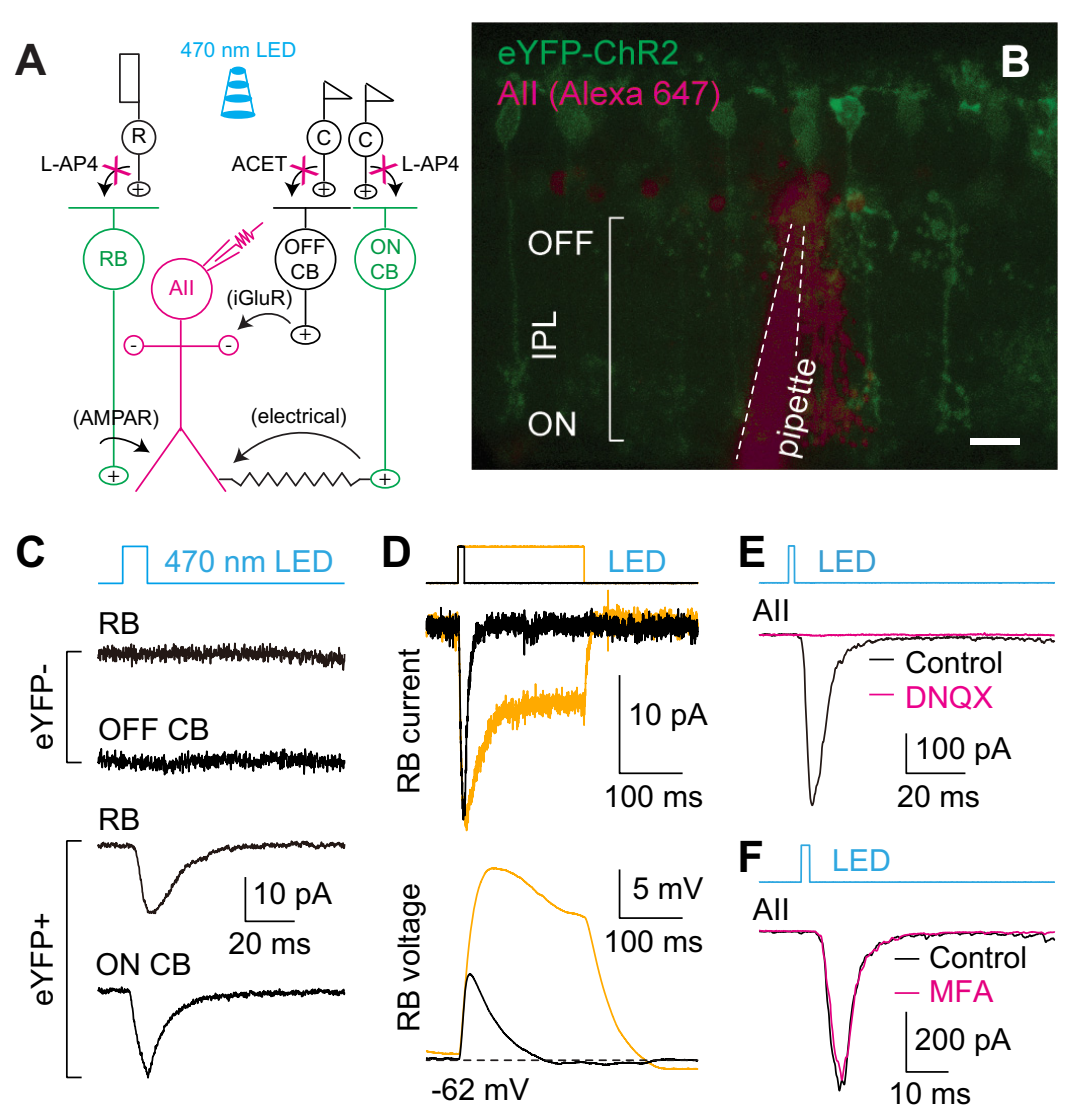

Figure 1. Optogenetic study of transmission at $\mathrm{RB} \rightarrow$ All synapses. $\boldsymbol{A}$, A diagram illustrating optogenetic study of synaptic transmission between RB cells and All amacrine cells in the retinas of Pcp2-cre::Ai32 mice. After synaptic transmission between photoreceptors and bipolar cells is blocked with L-AP4 and ACET, 470-nm light flashes could stimulate light-sensitive ChR2 channels and thus directly activate ChR2-eYFP-expressing RBs and ON CB cells (green), and finally evoked responses in postsynaptic All amacrine cells (magenta) could be recorded. B, A two-photon image showing ChR2-eYFP expression (green) in a retinal slice made from a Pcp2-cre::Ai32 mouse; an All amacrine cell (magenta) was recorded and filled with Alexa Fluor 647 by a patch pipette (outlined by dashed lines). Scale bar: $10 \mu \mathrm{m}$. C, Representative traces showing ChR2-mediated currents recorded in an eYFP+ RB and an eYFP+ ON CB, but not in either eYFP- RB or eYFP- OFF CB, during brief flashes of $470-\mathrm{nm}$ LED. $\mathrm{V}_{\text {hold }}=-60 \mathrm{mV}$. $\boldsymbol{D}$, Representative traces showing ChR2-mediated current (voltage-clamp mode; $\mathrm{V}_{\text {hold }}=-60 \mathrm{mV}$ ) and membrane potential (voltage; current-clamp mode) changes recorded in an eYFP+RB during brief (10 ms) and long (200 ms) light stimuli. $\boldsymbol{E}$, During brief flashes, the eEPSCs recorded in All amacrine cells postsynaptic to RBs were blocked almost completely by DNQX (20 $\mu \mathrm{M})$. $\boldsymbol{F}$, The eEPSCs recorded during brief flashes were only slightly influenced by the gap junction blocker, MFA (100 $\mu \mathrm{M})$.

Student's $t$ test, Wilcoxon signed-rank test or MannWhitney test where appropriate. Significance was taken as $p<0.05$. All data were illustrated as mean \pm SEM.

\section{Results}

\section{Optogenetic control of transmission at the RB $\rightarrow$ All synapse}

To permit transmission at $\mathrm{RB} \rightarrow$ All synapses to be evoked reliably over extended experimental periods, we used an optogenetic approach in which ChR2 was expressed in RBs by cre-mediated recombination in Pcp2cre::Ai32 mouse retinas (Fig. 1A). As reported previously (Zhang et al., 2005; Ivanova et al., 2010), expression of ChR2-eYFP was observed in ON bipolar cells, largely RBs, in in vitro retinal slices prepared from these animals (Fig. $1 B$ ). With synaptic transmission between photoreceptors and bipolar cells blocked with the mGluR6 agonist L-AP4 (2 $\mu \mathrm{M}$; to block photoreceptor $\rightarrow$ ON bipolar cell synapses, including rod $\rightarrow$ RB synapses) and the kainate receptor antagonist ACET [1 $\mu \mathrm{m}$; to block photoreceptor $\rightarrow$ OFF cone bipolar (CB) cell synapses; Park et al., 2018, 2020], 470-nm light induced ChR2-mediated currents in eYFP+ RBs and ON CBs, but not in eYFP- RBs and OFF CBs (Fig. 1C). Changes in light intensity and stimulus duration modulated ChR2-mediated current and membrane potential changes in RBs (Fig. 1D). Most importantly, brief flashes (e.g., $1-10 \mathrm{~ms}$ ) evoked EPSCs in All amacrine cells. The EPSCs recorded in Alls were abolished almost completely by nonNMDA glutamate receptor antagonist DNQX $(20 \mu \mathrm{M}$; Fig. $1 E)$, which blocks transmission at $\mathrm{RB} \rightarrow$ All synapses (Singer and Diamond, 2003). In contrast, the EPSCs were only slightly affected by MFA (100 $\mu \mathrm{M}$; Fig. $1 F)$, which blocks the gap junctions between All amacrine cells and ON CBs (Veruki and Hartveit, 2009). Overall, these results indicated that optogenetic control of transmission at $\mathrm{RB} \rightarrow$ All synapse was achieved reliably. Light-evoked EPSCs (termed eEPSCs hereafter) were quite stable over 
long periods ( $>20 \mathrm{~min}$ ), which allowed us to assess regulation of neurotransmitter release at $\mathrm{RB} \rightarrow$ All synapses.

\section{A CaM antagonist affects evoked and spontaneous release differently}

Physiologic depolarization of RB terminals results in $\mathrm{Ca}^{2+}$ influx sufficient to raise intracellular $\left[\mathrm{Ca}^{2+}\right]$ to levels that saturate endogenous buffers (Mehta et al., 2014). Given that CaM is both a well-characterized $\mathrm{Ca}^{2+}$ sensor and a modulator of synaptic transmission (Chanaday and Kavalali, 2018), we postulated that were CaM expressed in RB terminals, it would play a significant role in modulating transmission at $\mathrm{RB} \rightarrow$ All synapses.

We therefore performed immunofluorescence double labeling of CaM and PKC $\alpha$ (a specific marker of RBs), and we found that CaM was strongly expressed in the axon terminals and, to a lesser extent, in the somata of RBs (Fig. 2A1,A2). Interestingly, RBs seemed to have the highest CaM expression level, especially in their axon terminals, among all retinal cell types, suggesting that CaM might play a prominent role in presynaptic functions (Pangrsic et al., 2018).

It has been reported that $\mathrm{CaBP} 5$, with $\sim 58 \%$ sequence similarity to CaM, also is expressed in mouse RBs; because it interacts with Munc18-1 and myosin VI, both of which are involved in synaptic vesicle cycle, it has been suggested that CaBP5 may play a modulatory role in synaptic transmission (Haeseleer et al., 2000; Rieke et al., 2008; Sokal and Haeseleer, 2011). Preincubation of the anti-CaM antibody with the CaBP5 peptide, however, did not change the staining pattern for $\mathrm{CaM}$ as the CaM peptide did (Fig. 2A2,A3), indicating that the anti-CaM antibody used in this study did not cross-react with CaBP5 proteins.

We recorded miniature EPSCs (mEPSCs) and eEPSCs in Alls, which reflect spontaneous and evoked neurotransmitter release from RBs, respectively, and assessed the effect of modulating CaM. Remarkably, bath application of a CaM antagonist, W-7 (50 $\mu \mathrm{M})$ had strong, distinct effects on mEPSCs and eEPSCs: $W-7$ strongly increased mEPSC frequency (Fig. 2B1) while dramatically suppressing eEPSC amplitude (Fig. 2B1,B2). We also tested the effect of W-7 on mEPSCs in wt mice. Since there were no visible differences between the Pcp2-cre::Ai32 and wt mouse data, they were pooled. The effects of $W-7$ on eEPSCs $(n=9$ for $50 \mu \mathrm{M} ; n=6$ for $25 \mu \mathrm{M}$; Fig. 2B3) and mEPSCs $(n=15$ for $50 \mu \mathrm{m} ; n=13$ for $25 \mu \mathrm{m} ; n=8$ for 10 $\mu \mathrm{M}$; Fig. 2C1) were both time and concentration dependent. W-7, however, had no obvious effect on mEPSC amplitude ( $n=15$ for $50 \mu \mathrm{m} ; n=13$ for $25 \mu \mathrm{M} ; n=8$ for $10 \mu \mathrm{M}$; Fig. 2C2), indicating that inhibition of presynaptic CaM strongly enhanced spontaneous release from RB terminals. Note that DMSO alone, at the same concentration as was present with $50 \mu \mathrm{M} \mathrm{W}-7$, did not change the eEPSC amplitude (Fig. 2B3), mEPSC frequency (Fig. 2C1), or mEPSC amplitude (Fig. 2C2).

To strengthen our conclusion that suppression of eEPSCs by $\mathrm{W}-7$ arose from a presynaptic mechanism, we recorded the postsynaptic AMPA receptor-mediated currents in Alls evoked by glutamate (1 $\mathrm{mm})$ applied directly onto the All dendrites located at the border of the IPL and ganglion cell layer (GCL) when $\mathrm{CoCl}_{2}(1 \mathrm{~mm})$ was included in the external solution to block all $\mathrm{Ca}^{2+}$-dependent synaptic transmission: $50 \mu \mathrm{M} \mathrm{W}-7$ had no significant effect on the glutamate-evoked postsynaptic currents ( $n=7$; Figs. $2 D 1, D 3$ ). Notably, although $\mathrm{CoCl}_{2}$ should have blocked all VGCCs, W-7 still increased mEPSC frequency (Fig. 2D2); this result is explored further, below.

We also tested the effects of CMZ, another CaM antagonist, and CALP1, a CaM agonist (Villain et al., 2000), on eEPSCs and mEPSCs. Application of CMZ $(100 \mu \mathrm{M})$, to a lesser extent, reduced eEPSC amplitude (control vs CMZ, 1.00 vs $0.70, n=12$ and $p=0.0005$ by Wilcoxon signed-rank test; control vs $W-7,1.00$ vs $0.28, n=9$ and $p=0.0039$ by Wilcoxon signed-rank test; Fig. 2E), but it did not change the mEPSC frequency (control vs CMZ, 1.00 vs $0.96, n=11$ and $p=0.6377$ by Wilcoxon signedrank test; Fig. 2F). Application of CALP1 (1 $\mu \mathrm{M})$ for $15 \mathrm{~min}$, however, did not change the eEPSC amplitude (control vs CALP1, 1.00 vs $0.98, n=5$ and $p=0.6250$ by Wilcoxon signed-rank test; Fig. 2E), but it slightly reduced mEPSC frequency (control vs CALP1, 1.00 vs $0.85, n=9$ and $p=0.0273$ by Wilcoxon signed-rank test; by contrast, control vs $W-7,1.00$ vs $5.95, n=15$ and $p<0.0001$ by Wilcoxon signed-rank test; Fig. 2F). These results suggest that CaM is activated tonically by physiological $\mathrm{Ca}^{2+}$ influx into RB terminals under our experimental conditions.

Inhibition of $\mathrm{CaM}$ inhibits evoked transmission and stimulates spontaneous release at $\mathrm{RB} \rightarrow$ All synapses. Imaging exocytosis from bipolar cell terminals has led to the conclusion that evoked and spontaneous release might arise from physically separate presynaptic sites (Midorikawa et al., 2007; Zenisek, 2008), with spontaneous release occurring farther from the ribbon-type AZ than evoked release. The expression pattern of CaM in the axon terminals of RBs (Fig. 2A1) supports a role as a dual regulator of evoked and spontaneous release. Immunofluorescence double labeling of CaM and CtBP2/RIBEYE, a unique scaffolding protein of ribbons (Maxeiner et al., 2016), showed CaM to be expressed ubiquitously, at sites both near and away from ribbons (Fig. 3).

\section{Inhibition of CaM suppresses Ca currents in RB terminals}

The similarity of the observations made in Pcp2-cre:: Ai32 and wt retinas indicated that the effect of W-7 on spontaneous release was not influenced by exogenous expression of ChR2-eYFP in RBs. To further exclude the possibility that the effect of $\mathrm{W}-7$ on evoked release might be because of exogenous ChR2-eYFP expression, we evoked EPSCs in All amacrine cells from wt mice by puffing the mGluR6 antagonist LY 341495 (LY; 5-10 $\mu \mathrm{M}$ ) onto $\mathrm{RB}$ dendrites located at the OPL, and then assessed the effect of applied W-7. Not surprisingly, W-7 (50 $\mu \mathrm{M})$ strongly reduced the LY-evoked EPSCs (Fig. 4A1) with a seemingly slower time course (Fig. 4A2). We reasoned that $L Y$ application elicited larger changes in presynaptic $\left[\mathrm{Ca}^{2+}\right]$ than did brief light stimuli, as evidenced from the 
A1
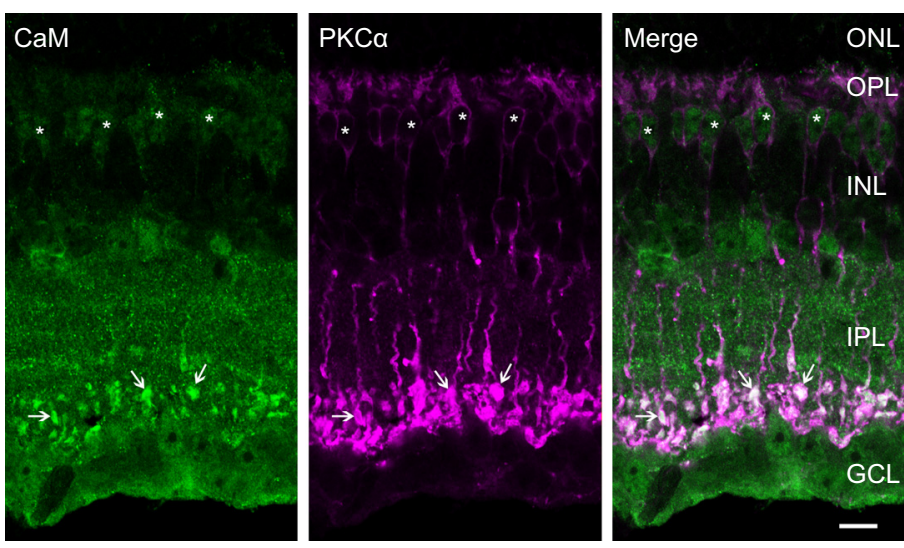

A2

pre

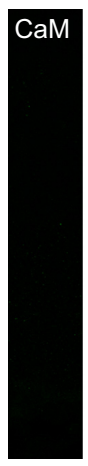

A3

CaBP5 peptide pre-adsorption

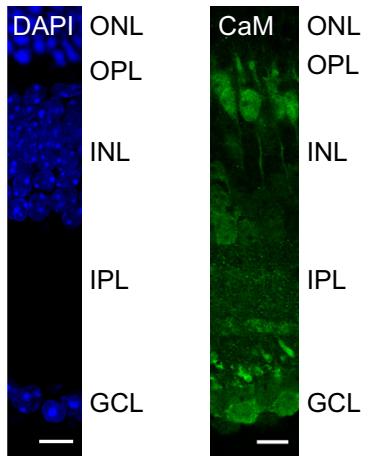

B1

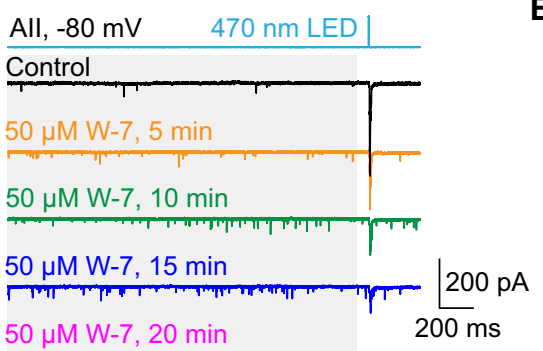

C1

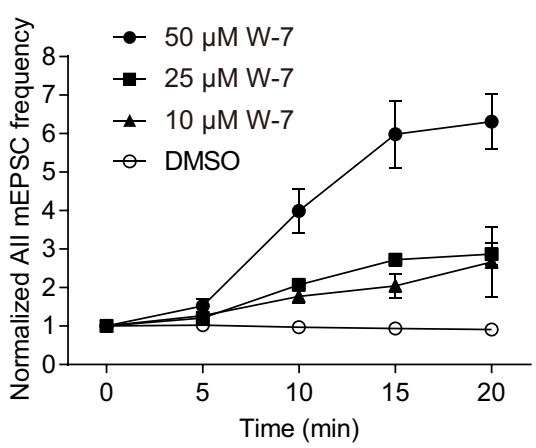

B2

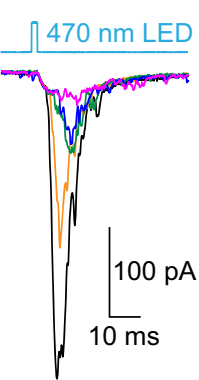

B3

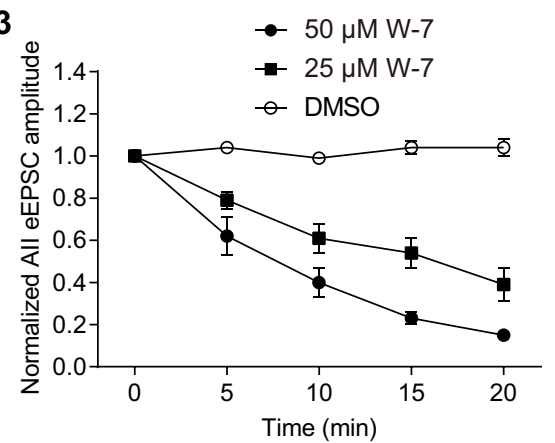

C2

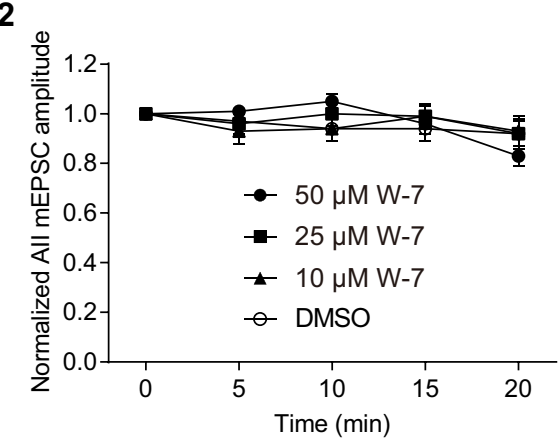

D1

D3

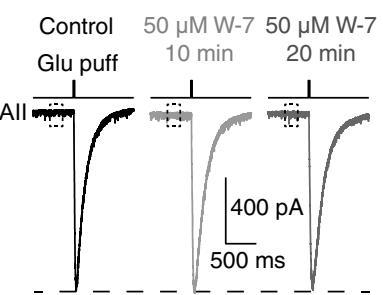

D2

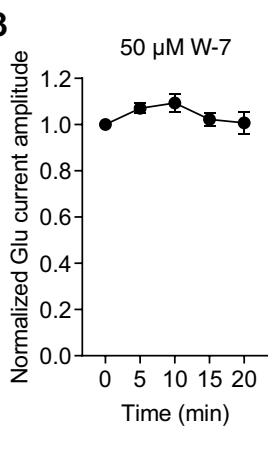

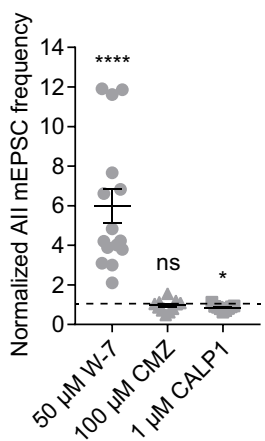

Figure 2. CaM bidirectionally regulates evoked and spontaneous neurotransmitter release from RBs. A1, Confocal images showing immunofluorescence double labeling of CaM (green) and PKC $\alpha$ (magenta), a specific cell marker of RBs, in a frozen retinal slice. In the merged image (green + magenta), expression of CaM could be clearly seen in the axon terminals (arrow) and somata (asterisk) of RBs. Scale bar: $10 \mu \mathrm{m}$. ONL: outer nuclear layer; OPL: outer plexiform layer; INL: inner nuclear layer; IPL: inner plexiform layer; GCL: ganglion cell layer. A2, No labeling was observed in the negative control where the anti-CaM antibody was preincubated with the CaM immunopeptide. DAPI staining showed the three major cell body layers in the retina. Scale bar: $10 \mu \mathrm{m}$. $\boldsymbol{A 3}$, Preadsorption of the anti-CaM antibody with the CaBP5 immunopeptide did not change the staining pattern for CaM. Scale bar: $10 \mu \mathrm{m}$. B1, Twomillisecond flashes of 470-nm LED were presented to stimulate ChR2 in Pcp2-cre::Ai32 mice with L-AP4 and ACET in the bath to 
continued

block synaptic transmission between photoreceptors and bipolar cells; all the inhibitory connections were also blocked. The evoked responses (eEPSCs) and the small responses induced by spontaneous release before light onset (mEPSCs; see gray background area) in All amacrine cells were recorded. $\mathrm{V}_{\text {hold }}=-80 \mathrm{mV}$. Individual traces showed that the CaM antagonist, W-7 (50 $\left.\mu \mathrm{M}\right)$ strongly increased mEPSC frequency and reduced eEPSC amplitude. B2, Average traces of eEPSCs recorded in the same All in B1. B3, Statistics of the effects of $25 \mu \mathrm{M}(n=6)$ and $50 \mu \mathrm{M}(n=9) \mathrm{W}-7$ on eEPSC amplitude. The amplitudes were normalized to the amplitude at time 0 in each cell before averaging across cells. C1, Statistics of the effects of $10 \mu \mathrm{M}(n=8), 25 \mu \mathrm{M}(n=13)$, and $50 \mu \mathrm{M}$ $(n=15) \mathrm{W}-7$ on mEPSC frequency. The frequencies were normalized to the frequency at time 0 in each cell before averaging across cells. C2, Statistics of the effects of $10 \mu \mathrm{M}(n=8), 25 \mu \mathrm{M}(n=13)$, and $50 \mu \mathrm{M}(n=15) \mathrm{W}-7$ on mEPSC amplitude. The amplitudes were normalized to the amplitude at time 0 in each cell before averaging across cells. D1, Individual traces showing that W-7 (50 $\mu \mathrm{M})$ had no inhibitory effect on AMPA receptor-mediated currents recorded in an All evoked by glutamate (1 mM) applied onto the All dendrites at the border of the IPL and GCL. $V_{\text {hold }}=-80 \mathrm{mV}$. D2, Magnification of the traces in the dashed line frames of $\boldsymbol{D 1}$, showing increase of mEPSC frequency by W-7. D3, Statistics of the effects of $50 \mu \mathrm{M} \mathrm{W}-7(n=7)$ on the amplitude of glutamate-evoked currents. The amplitudes were normalized to the amplitude at time 0 in each cell before averaging across cells. $\boldsymbol{E}$, Summary data showing the effects of $50 \mu \mathrm{M} \mathrm{W}-7$ (circles), $100 \mu \mathrm{M} \mathrm{CMZ}$ (triangles), another CaM antagonist, and $1 \mu \mathrm{M}$ CALP1 (squares), a CaM agonist, on eEPSC amplitude after bath application for $15 \mathrm{~min}$. The amplitudes were normalized to the amplitude at time 0 in each cell before averaging across cells. The data were also illustrated as mean \pm SEM. Wilcoxon signed-rank tests were used (control vs W-7, $n=9, p=0.0039$; control vs CMZ, $n=12, p=0.0005$; control vs CALP1, $n=5, p=0.6250$ ); ${ }^{* \star} p<0.01$, ${ }^{\star * \star} p<0.001$; ns: not statistically different. Note that CMZ reduced eEPSC amplitude too, but CALP1 did not enhance eEPSC amplitude under control conditions. $\boldsymbol{F}$, Summary data showing the effects of $50 \mu \mathrm{M} \mathrm{W}-7$ (circles), $100 \mu \mathrm{M} \mathrm{CMZ}$ (triangles), and $1 \mu \mathrm{M}$ CALP1 (squares) on mEPSC frequency. The frequencies were normalized to the frequency at time 0 in each cell before averaging across cells. The data were also illustrated as mean \pm SEM. Wilcoxon signed-rank tests were used (control vs W-7, $n=15, p<0.0001$; control vs CMZ, $n=12$, $p=0.6377$; control vs CALP1, $n=9, p=0.0273$ ); ${ }^{\star} p<0.05$, ${ }^{\star \star \star \star} p<0.0001$; ns: not statistically different. Note that CMZ did not change the mEPSC frequency, but activation of CaM by CALP1 slightly reduced mEPSC frequency.

large difference in the integrals of the EPSCs evoked by the two (integral of LY-evoked EPSCs, $830737 \pm 167550$, $n=7$; integral of ChR2-driven EPSCs, $3929 \pm 419, n=9$ ).

Given that both LY-evoked EPSCs (Fig. 4B) and lightevoked EPSCs (Fig. 4C) were abolished, as expected, by removal of extracellular $\mathrm{Ca}^{2+}\left(0 \mathrm{Ca}^{2+}\right.$; with 2 or $5 \mathrm{~mm}$ EGTA in the external solution), we tested the hypothesis that inhibition of $\mathrm{CaM}$ reduced evoked release by suppressing presynaptic $\mathrm{Ca}^{2+}$ influx. Depolarization of an $\mathrm{RB}$ with brief voltage step from -60 to $-20 \mathrm{mV}$ for $50 \mathrm{~ms}$ elicited sustained, inward Ca current ( $\mathrm{I}_{\mathrm{Ca}} ; 22.18 \pm 2.16 \mathrm{pA}$, $n=7$; Fig. 4D1). Both the peak amplitude and integral of $\mathrm{RB} \mathrm{I}_{\mathrm{Ca}}$ were reduced substantially by bath application of $50 \mu \mathrm{M} \mathrm{W}-7$ (Fig. 4D2). The time course of suppression of $R B \mathrm{I}_{\mathrm{Ca}}$ was strikingly consistent with that of inhibition of eEPSCs by $50 \mu \mathrm{M}$ W-7 (Fig. 4D2). Application of DMSO alone seemed to reduce slightly but insignificantly the peak amplitude of $\mathrm{RB} \mathrm{I}_{\mathrm{Ca}}$ (Fig. 4D2).

To ensure that whole-cell recording from the RB did not alter modulation of presynaptic $\mathrm{Ca}$ channels, we imaged $\left[\mathrm{Ca}^{2+}\right]$ in RB terminals of Pcp2-cre::Ai38 mice in which the fluorescent $\left[\mathrm{Ca}^{2+}\right]$ indicator GCaMP3 was expressed (see Materials and Methods). Brief application (6-50 ms) of LY (5-10 $\mu \mathrm{M})$ at the OPL depolarized RB dendrites, ultimately evoking strong fluorescence signals in RB axon terminals; these returned to baseline level after $\sim 5 \mathrm{~s}$ (Fig. $4 E 1$, control). The LY-evoked $\mathrm{Ca}^{2+}$ signals, detected by GCaMP3, were strongly reduced by application of $50 \mu \mathrm{M}$ W-7 (Fig. 4E1-E3), consistent with our observations of $\mathrm{Ca}$ currents (Fig. 4D1,D2).

Taken together, these results proved our hypothesis that inhibition of CaM strongly reduced evoked release from RBs by suppressing $\mathrm{Ca}^{2+}$ influx into axon terminals.

\section{Both $\mathrm{Ca}^{2+}$-dependent and $\mathrm{Ca}^{2+}$-independent spontaneous release are enhanced, with the latter to a greater extent, when CaM is inhibited}

The presynaptic mechanisms underlying spontaneous release of neurotransmitters have been studied for decades (Fatt and Katz, 1950, 1952; Kavalali, 2015). Spontaneous release at RB $\rightarrow$ All synapses depends on extracellular $\mathrm{Ca}^{2+}$ concentration, indicating that it is driven in part by $\mathrm{Ca}^{2+}$ influx through $\mathrm{Ca}$ channels that open spontaneously at resting potential (Singer et al., 2004; Mehta et al., 2013; Maxeiner et al., 2016; Mortensen et al., 2016). But, because spontaneous
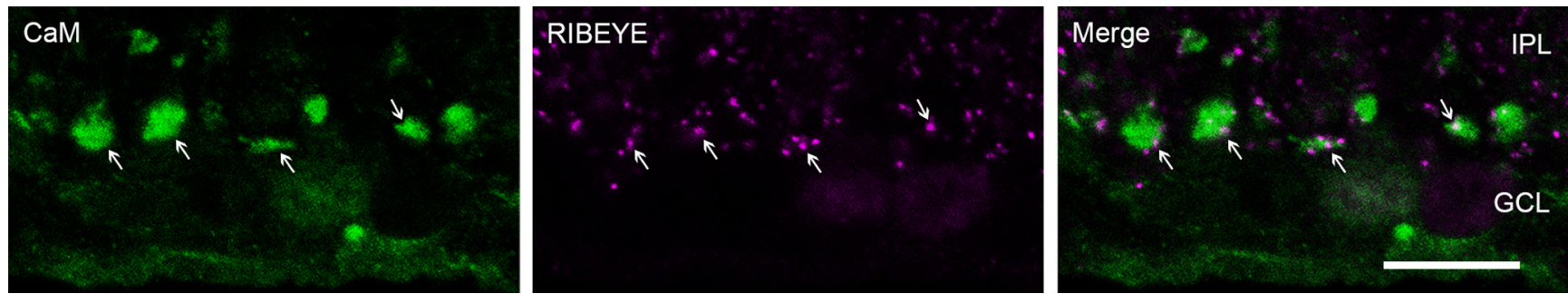

Figure 3. CaM is ubiquitously expressed at sites both near and away from ribbons in RB axon terminals. Confocal images showing immunofluorescence double labeling of CaM (green) and RIBEYE (magenta), a ribbon-specific protein, in the axon terminals of RBs. In the merged image (green + magenta), expression of CaM can be seen near ribbons (arrow) and away from ribbon sites. IPL: inner plexiform layer; GCL: ganglion cell layer. Scale bar: $10 \mu \mathrm{m}$. 

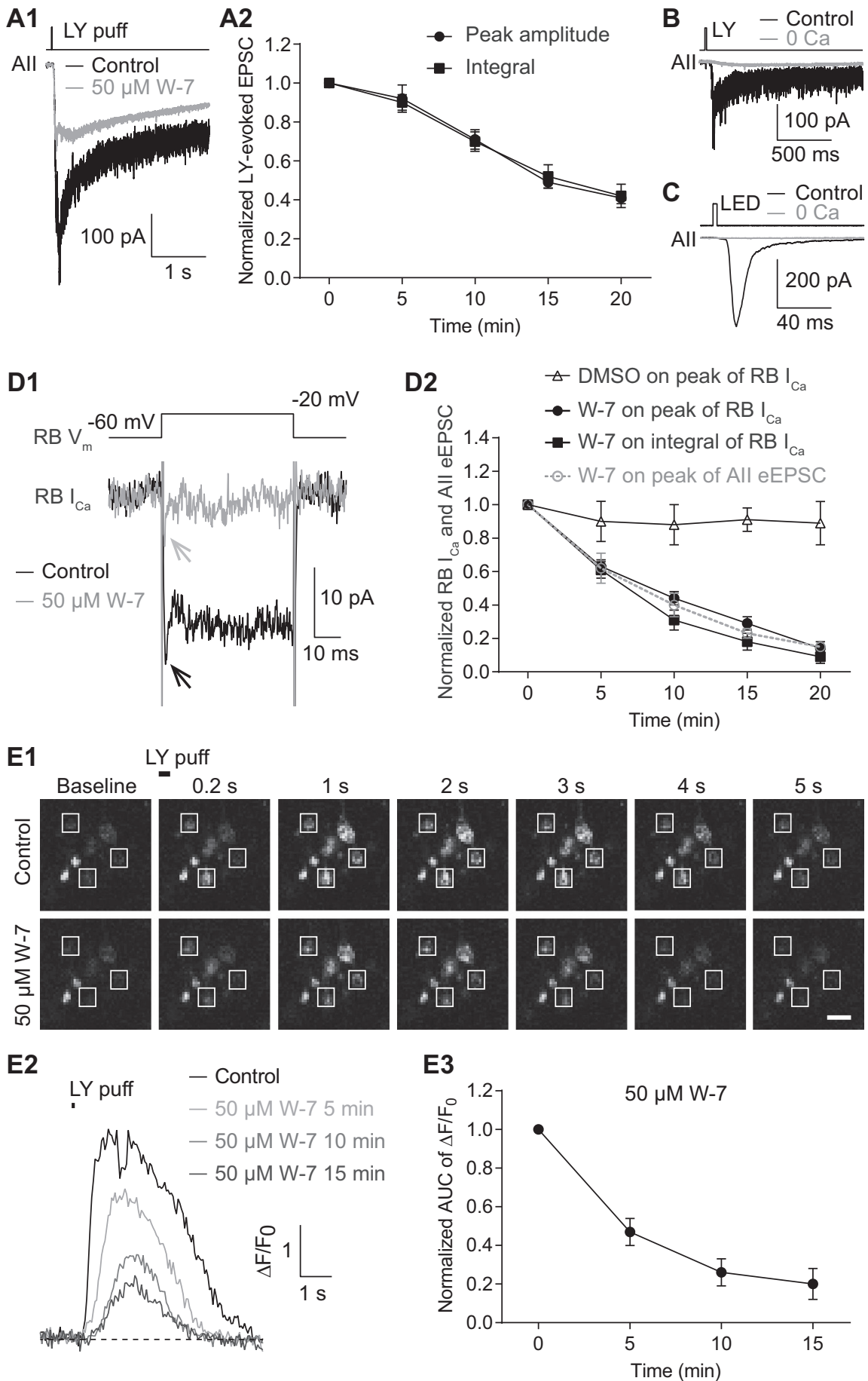

Figure 4. Inhibition of CaM strongly reduces evoked release from RBs by suppressing $\mathrm{Ca}^{2+}$ influx into their axon terminals. $\boldsymbol{A 1}$, Average traces showing that EPSCs recorded in an All, evoked by puffing LY 341495 (LY), an mGluR6 antagonist, onto the dendrites of RBs located at the OPL, were strongly reduced by application of $50 \mu \mathrm{M} \mathrm{W}-7$. V creased over time with application of $50 \mu \mathrm{M} \mathrm{W}-7(n=7)$. The peak amplitudes and integrals of EPSCs were normalized to the amplitude and integral at time 0 , respectively, in each cell before averaging across cells. $\boldsymbol{B}$, LY-evoked EPSCs were completely abolished by removing extracellular $\mathrm{Ca}^{2+}(0 \mathrm{Ca})$. C. The EPSCs recorded in an All, evoked by brief flashes of $470-\mathrm{nm}$ LED in a Pcp2-cre::Ai32 mouse, were abolished completely by removing extracellular $\mathrm{Ca}^{2+}(0 \mathrm{Ca})$. D1, Average traces showing that W-7 (50 $\mu \mathrm{M})$ strongly suppressed the voltage step-generated Ca currents $\left(\mathrm{I}_{\mathrm{Ca}}\right)$ in an RB. D2, Statistics of the effects of $50 \mu \mathrm{M}$ W-7 ( $\left.n=7\right)$ and DMSO control on the peak amplitude and integral of $\mathrm{RB} \mathrm{I}_{\mathrm{Ca}}$. The suppression of $\mathrm{I}_{\mathrm{Ca}}$ recorded in RBs was closely related to the inhibition of eEPSCs recorded in Alls (data adapted from Fig. 2B3, superimposed in gray). E1, Calcium imaging pictures from a Pcp2cre::Ai38 mouse showing that LY-evoked changes of $\mathrm{Ca}^{2+}$ signals in RB axon terminals (white frames), detected by the Ca ${ }^{2+}$ indicator GCaMP3, were reduced strongly by application of $50 \mu \mathrm{M}$ W-7. Scale bar: $1 \mu \mathrm{m}$. E2, Representative $\Delta \mathrm{F} / \mathrm{F}_{0}$ traces showing suppression of $\mathrm{Ca}^{2+}$ signals in an RB axon terminal by $50 \mu \mathrm{M}$ W-7. E3, Summary data showing that LY-evoked Ca ${ }^{2+}$ signals in RB 
continued

axon terminals ( $n=21$ terminals from 3 retinal slices), measured as areas under the curve (AUCs) of $\Delta \mathrm{F} / \mathrm{F}_{0}$ traces, were strongly suppressed by $50 \mu \mathrm{m} \mathrm{W}-7$ over time. All the data were illustrated as mean \pm SEM.

release from RB terminals persists at an appreciable rate when external $\mathrm{Ca}^{2+}$ is removed (Mortensen et al., 2016), there appears to be $\mathrm{Ca}^{2+}$-independent component to the process.

Given that W-7 (50 $\mu \mathrm{M})$ increased mEPSC frequency after evoked transmission was blocked with $\mathrm{CoCl}_{2}(1 \mathrm{~mm}$; Fig. 2D2), it appeared that inhibition of CaM enhanced
$\mathrm{Ca}^{2+}$-independent spontaneous release. To validate this observation and to explore the potential underlying mechanisms, we tested the effects of $50 \mu \mathrm{m} \mathrm{W}-7$ on mEPSCs under four experimental conditions: (1) removal of extracellular $\mathrm{Ca}^{2+}\left(0 \mathrm{Ca}^{2+}\right.$ plus 2 or $5 \mathrm{~mm}$ EGTA in the external solution; Fig. 5A); (2) $0 \mathrm{Ca}^{2+}$ combined with bath application of $10 \mu \mathrm{m}$ BAPTA-AM, a cell membrane permeable
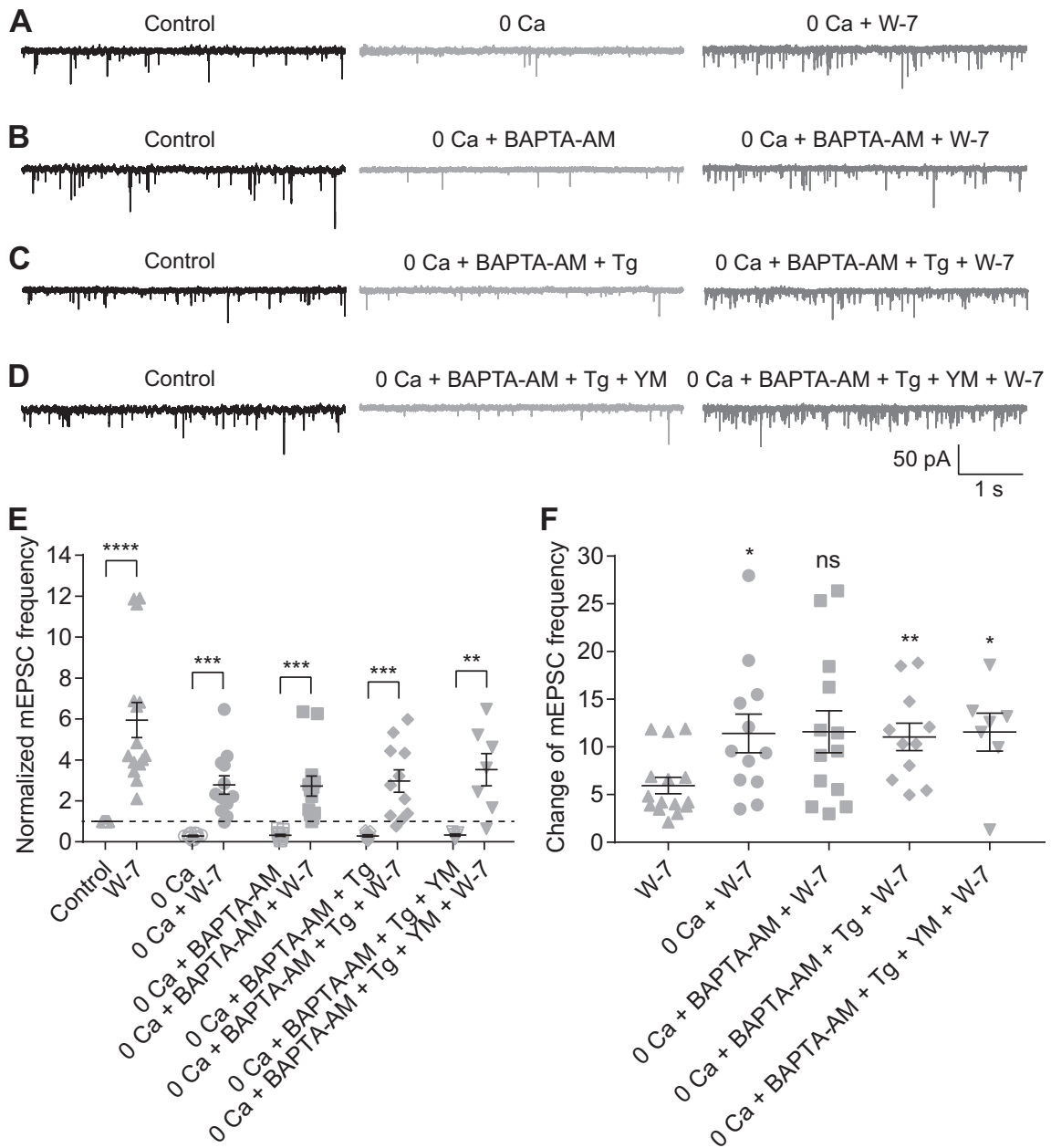

Figure 5. Both $\mathrm{Ca}^{2+}$-dependent and $\mathrm{Ca}^{2+}$-independent spontaneous release are enhanced, but to different extents, when CaM is inhibited. $\boldsymbol{A}-\boldsymbol{D}$, Representative traces showing mEPSCs recorded in Alls under four experimental conditions in different combinations of removal of extracellular calcium ( $0 \mathrm{Ca}$ ), $10 \mu \mathrm{M}$ BAPTA-AM, $1 \mu \mathrm{M}$ Tg, and $1 \mu \mathrm{M}$ YM-58483 (YM). The traces showing mEPSCs after bath application of $50 \mu \mathrm{M}$ W-7 for $15 \mathrm{~min}$ under each condition were also presented. $E$, Summary data for All mEPSC frequency under four experimental conditions in $\boldsymbol{A}-\boldsymbol{D}$. The data under control and W-7 conditions (adapted from Fig. 2C1, empty and full up triangles, respectively) were also presented for direct comparison. The frequencies were normalized to the frequency under control condition in each cell before averaging across cells. The data were also illustrated as mean \pm SEM. Paired Student's $t$ tests were used $(0 \mathrm{Ca}$ vs $0 \mathrm{Ca}+\mathrm{W}-7, n=12, p=0.0001 ; 0 \mathrm{Ca}+$ BAPTA-AM vs $0 \mathrm{Ca}+\mathrm{BAPTA}-\mathrm{AM}+\mathrm{W}-7, n=13, p=0.0002 ; 0 \mathrm{Ca}+$ BAPTA-AM + Tg vs $0 \mathrm{Ca}+$ BAPTA-AM + Tg + W-7, $n=11, p=0.0004 ; 0 \mathrm{Ca}+$ BAPTA-AM + Tg + YM vs 0 Ca + BAPTA-AM + $\mathrm{Tg}+\mathrm{YM}+\mathrm{W}-7, n=7, p=0.0062)$ except for comparison of control and $\mathrm{W}-7$ data by Wilcoxon signed-rank test $(n=15$, $p<0.0001) ;{ }^{\star *} p<0.01,{ }^{* \star *} p<0.001,{ }^{\star * * *} p<0.0001$. $\boldsymbol{F}$. Summary data for the relative effect of W-7 on All mEPSC frequency under control and four experimental conditions. The change in each cell was calculated as the ratio of mEPSC frequencies before and 15 min after application of $\mathrm{W}-7$. The data were also illustrated as mean \pm SEM. Mann-Whitney tests were used (W-7 vs 0 Ca + W7, $p=0.0214 ; \mathrm{W}-7$ vs $0 \mathrm{Ca}+$ BAPTA-AM $+\mathrm{W}-7, p=0.0954 ; \mathrm{W}-7$ vs $0 \mathrm{Ca}+$ BAPTA-AM + Tg $+\mathrm{W}-7, p=0.0045 ; \mathrm{W}-7$ vs 0 Ca + BAPTA-AM + Tg + YM + W-7, $p=0.0262) ;{ }^{*} p<0.05,{ }^{* *} p<0.01$; ns: not statistically different. 
Table 1: The effects of W-7 on All mEPSC frequency under different conditions

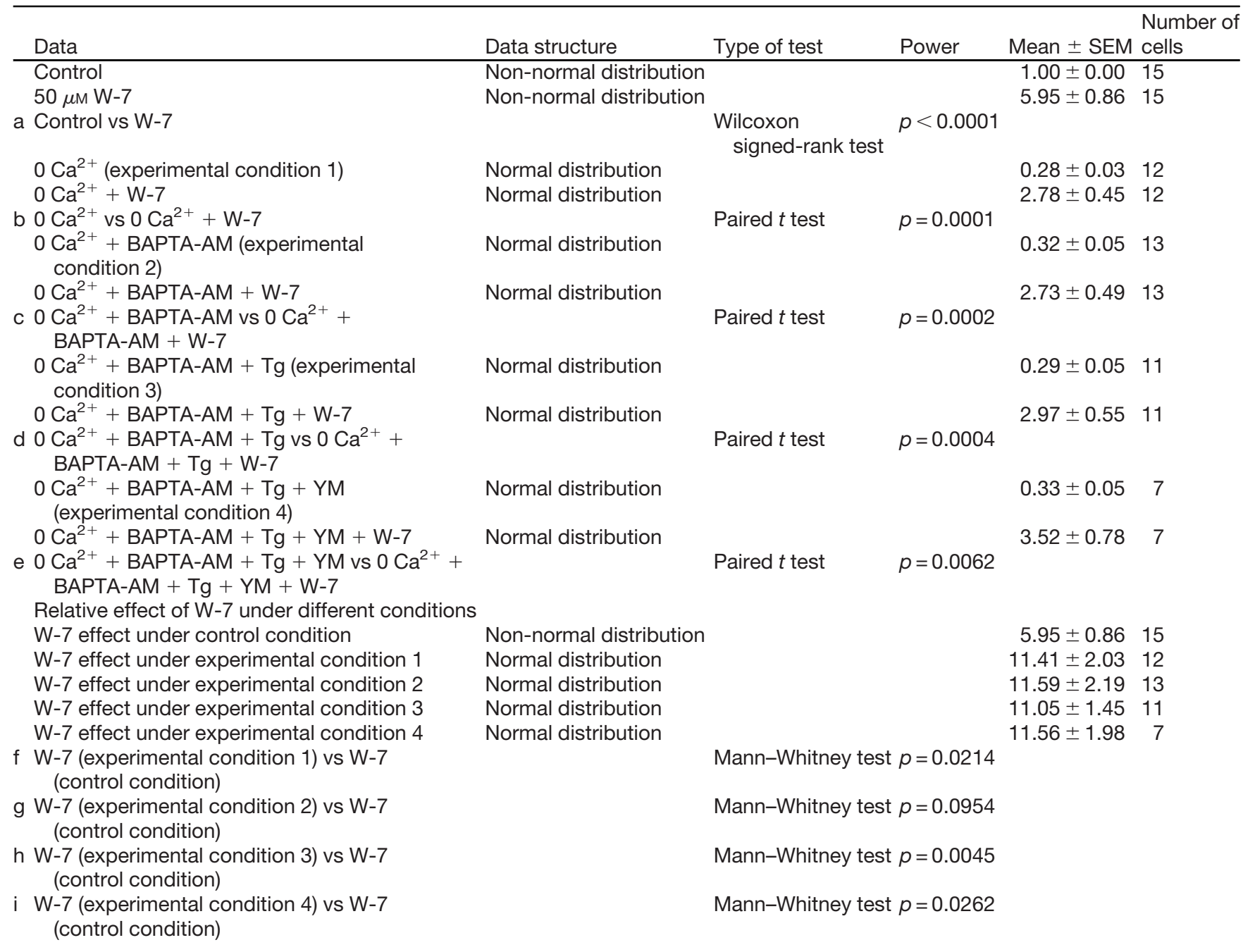

$0 \mathrm{Ca}^{2+}$ : remove extracellular $\mathrm{Ca}^{2+} ;$ YM: YM-58483.

$\mathrm{Ca}^{2+}$ chelator with rapid binding kinetics (Fig. 5B); (3) 0 $\mathrm{Ca}^{2+}, 10 \mu \mathrm{M}$ BAPTA-AM, and $1 \mu \mathrm{M}$ Tg, a sarco-endoplasmic reticulum $\mathrm{Ca}^{2+}$-ATPase inhibitor which depletes intracellular $\mathrm{Ca}^{2+}$ stores (Fig. 5C); and (4) $0 \mathrm{Ca}^{2+}, 10 \mu \mathrm{M}$ BAPTA-AM, $1 \mu \mathrm{M}$ Tg, and $1 \mu \mathrm{M}$ YM-58483, which inhibits calcium release-activated calcium channels (CRACs) and suppresses Tg-induced $\mathrm{Ca}^{2+}$ influx (Fig. 5D). For each condition, mEPSCs were recorded for at least $15 \mathrm{~min}$ before bath application of $50 \mu \mathrm{m} \mathrm{W}-7$. We analyzed mEPSCs recorded under control, experimental (one of the four detailed above), and experimental $+\mathrm{W}-7$ conditions. Under each of the four experimental conditions, mEPSC frequency was reduced strongly compared with control, but for each of the four, application of $50 \mu \mathrm{M} \mathrm{W}-7$ increased mEPSC frequency substantially (Fig. 5E; Table 1). The ratio of $\mathrm{mEPSC}$ frequencies before and after application of W-7 under each condition was also calculated (Fig. 5F; Table 1).

Additionally, we found that under experimental condition 1 (i.e., $0 \mathrm{Ca}^{2+}$ condition), $1 \mu \mathrm{M}$ CALP1 reduced average mEPSC frequency to $\sim 53 \%$ of control $(n=8$; $p=0.0078$ by Wilcoxon signed-rank test; control condition vs experimental condition $1, p=0.0027$ by unpaired Student's $t$ test). Interestingly, the relative effect on mEPSC frequency of either W-7 or CALP1 was stronger under experimental than control conditions, indicating that modulation of $\mathrm{CaM}$ influenced $\mathrm{Ca}^{2+}$-independent spontaneous release more strongly than $\mathrm{Ca}^{2+}$-dependent spontaneous release.

\section{Inhibition of MLCK, but not other CaM targets, closely mimics the distinct effects of CaM inhibition on evoked and spontaneous release}

Given that CaM modulates Ca channels directly (BenJohny and Yue, 2014), we wished to determine whether the effect of $\mathrm{W}-7$ was mediated by CaM acting directly on target proteins or indirectly, via a downstream second messenger. Therefore, we recorded simultaneously mEPSCs and ChR2-driven eEPSCs in All amacrine cells. Strikingly, bath application of a specific MLCK inhibitor, ML-9 (100 $\mu \mathrm{M})$ had strong, distinct effects on 


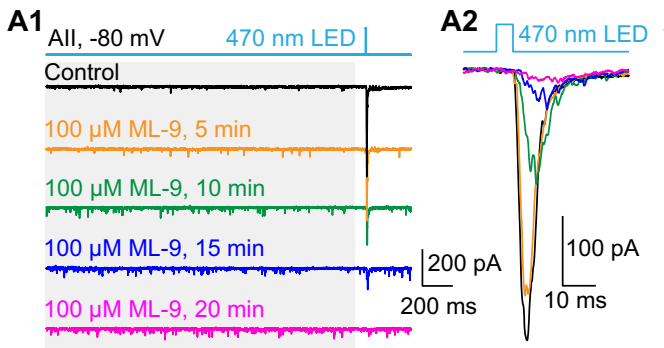

B1

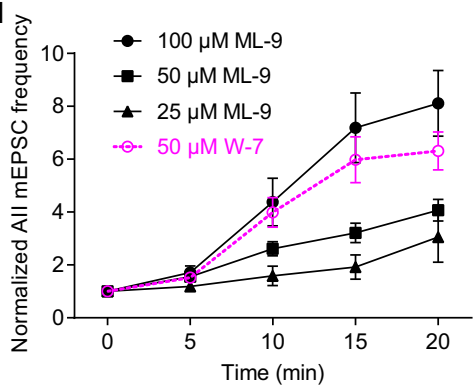

C1

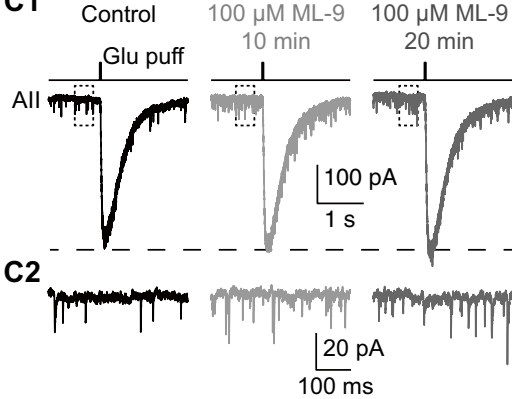

D

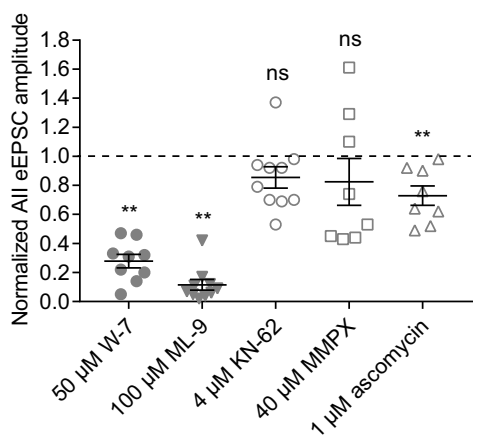

B2
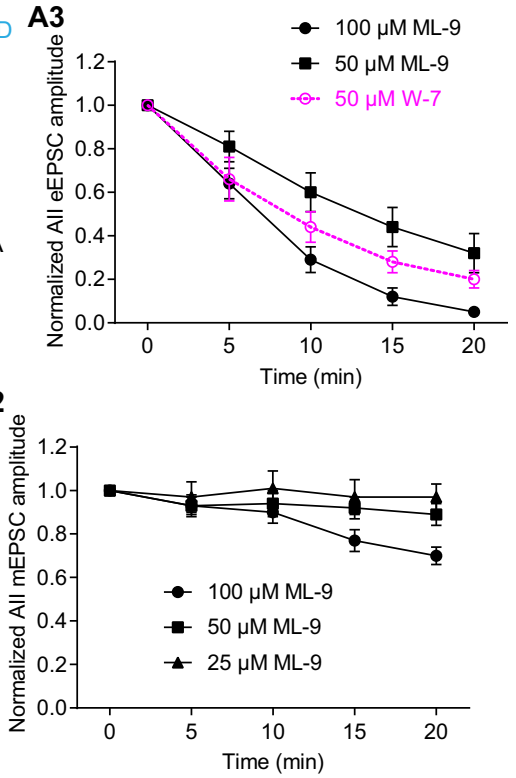

C3

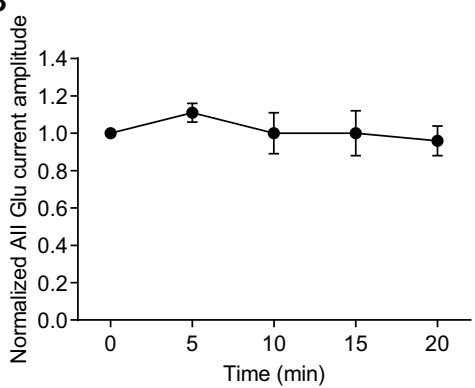

E

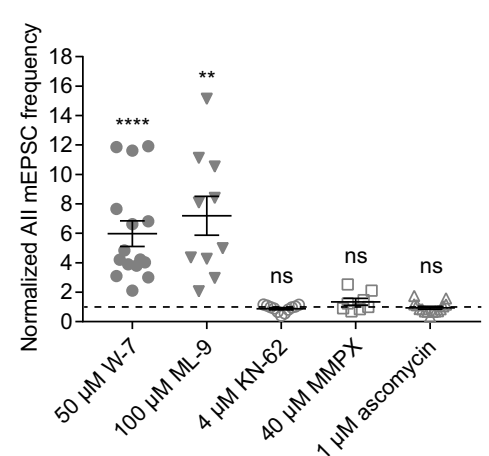

Figure 6. Inhibition of MLCK, but not other CaM targets, differentially regulates evoked and spontaneous release from RBs. A1, Five-millisecond flashes of 470-nm LED were presented to stimulate ChR2-expressing RBs in Pcp2-cre::Ai32 mice. The mEPSCs (in gray background area) and eEPSCs in Alls were recorded. $\mathrm{V}_{\text {hold }}=-80 \mathrm{mV}$. Individual traces showed that a specific MLCK inhibitor, ML-9 (100 $\mu \mathrm{M})$ strongly increased mEPSC frequency and reduced eEPSC amplitude. A2, Average traces of eEPSCs recorded in the same All in A1. A3, Statistics of the effects of $50 \mu \mathrm{M}(n=5)$ and $100 \mu \mathrm{M}(n=10)$ ML-9 on eEPSC amplitude. The amplitudes were normalized to the amplitude at time 0 in each cell before averaging across cells. The data of $50 \mu \mathrm{M} \mathrm{W}-7$ (adapted from Fig. 2B3, superimposed in magenta) were also included for direct comparison. B1. Statistics of the effects of $25 \mu \mathrm{M}(n=7), 50 \mu \mathrm{M}(n=13)$, and 100 $\mu \mathrm{M}(n=10) \mathrm{ML}-9$ on mEPSC frequency. The frequencies were normalized to the frequency at time 0 in each cell before averaging across cells. The data of $50 \mu \mathrm{m} \mathrm{W-7} \mathrm{(adapted} \mathrm{from} \mathrm{Fig.} \mathrm{2C1,} \mathrm{superimposed} \mathrm{in} \mathrm{magenta)} \mathrm{were} \mathrm{also} \mathrm{included} \mathrm{for} \mathrm{direct} \mathrm{comparison.}$ B2, Statistics of the effects of $25 \mu \mathrm{M}(n=7), 50 \mu \mathrm{M}(n=13)$, and $100 \mu \mathrm{M}(n=10)$ ML-9 on mEPSC amplitude. The amplitudes were normalized to the amplitude at time 0 in each cell before averaging across cells. C1, Individual traces showing that ML-9 (100 $\mu \mathrm{M})$ had no inhibitory effect on AMPA receptor-mediated currents recorded in an All evoked by glutamate $(1 \mathrm{~mm})$ applied onto the All dendrites at the border of the IPL and GCL. $V_{\text {hold }}=-80 \mathrm{mV}$. C2, Magnification of the traces in the dashed line frames of C1, showing increase of mEPSC frequency by ML-9. C3. Statistics of the effects of $100 \mu \mathrm{M} \mathrm{ML-9}(n=4)$ on the amplitude of glutamate-evoked currents. The amplitudes were normalized to the amplitude at time 0 in each cell before averaging across cells. $\boldsymbol{D}$, Summary data showing the effects of bath application of W-7 (50 $\mu \mathrm{M}$; full circles; adapted from Fig. 2E), ML-9 (100 $\mu \mathrm{M}$; full down triangles), KN-62

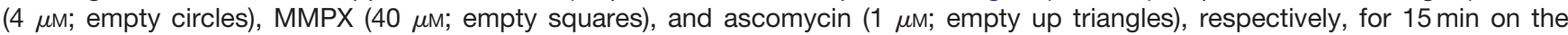


continued

amplitude of eEPSCs recorded in Alls. In each group of data, the amplitudes were normalized to the amplitude before application of a drug in each cell before averaging across cells. The data were also illustrated as mean \pm SEM. Wilcoxon signed-rank tests were used (control vs W-7, $n=9, p=0.0039$; control vs ML-9, $n=10, p=0.0020$; control vs KN-62, $n=10, p=0.0586$; control vs MMPX, $n=8, p=0.4609$; control vs ascomycin, $n=8, p=0.0078$ ); ${ }^{* *} p<0.01$, ${ }^{* * *} p<0.0001$; ns: not statistically different. $\boldsymbol{E}$, Summary data showing the effects of bath application of W-7 (50 $\mu \mathrm{M}), \mathrm{ML}-9(100 \mu \mathrm{M}), \mathrm{KN}-62(4 \mu \mathrm{M}), \mathrm{MMPX}(40 \mu \mathrm{M})$, and ascomycin $(1 \mu \mathrm{M})$ for $15 \mathrm{~min}$ on $\mathrm{mEPSC}$ frequency. In each group of data, the frequencies were normalized to the frequency before application of a drug in each cell before averaging across cells. The data were also illustrated as mean \pm SEM. Wilcoxon signed-rank tests were used (control vs W-7, $n=15, p<0.0001$; control vs ML-9, $n=10, p=0.0020$; control vs KN-62, $n=11, p=0.2139$; control vs MMPX, $n=8$, $p=0.3828$; control vs ascomycin, $n=15, p=0.3591)$; ${ }^{* *} p<0.01$, ${ }^{\star \star \star *} p<0.0001$; ns: not statistically different.

mEPSCs and eEPSCs, reminiscent of the effects of W7: ML-9 strongly increased mEPSC frequency (Fig. 6A1) while dramatically suppressing eEPSC amplitude (Fig. $6 A 1, A 2)$. The effects of ML-9 on eEPSCs ( $n=10$ for 100 $\mu \mathrm{M} ; n=5$ for $50 \mu \mathrm{M}$; Fig. $6 A 3)$ and mEPSCs $(n=10$ for $100 \mu \mathrm{M} ; n=13$ for $50 \mu \mathrm{M} ; n=7$ for $25 \mu \mathrm{M}$; Fig. 6B1) were both time and concentration dependent. ML-9, also, seemed to have a weakly inhibitory effect on mEPSC amplitude, especially at high concentrations ( $n=10$ for $100 \mu \mathrm{M} ; n=13$ for $50 \mu \mathrm{M} ; n=7$ for $25 \mu \mathrm{M}$; Fig. 6B2). We conclude that inhibition of MLCK strongly enhanced spontaneous release from RB axon terminals.

To exclude the possibility that the suppression of eEPSCs by ML- 9 was because of a postsynaptic effect, we recorded AMPA receptor-mediated currents evoked by pressure ejection of glutamate $(1 \mathrm{~mm})$ onto All dendrites when $\mathrm{CoCl}_{2}(1 \mathrm{~mm}$ ) was included in the external solution to block synaptic transmission. As was the case with W-7, $100 \mu \mathrm{M}$ ML-9 had little effect on the glutamate-evoked currents ( $n=4$; Fig. $6 C 1, C 3)$. Notably ML-9 still increased mEPSC frequency even when $\mathrm{Ca}$ channels were blocked with $\mathrm{CoCl}_{2}$ in the external solution (Fig. 6C2).
We also examined the effects of inhibitors of other downstream CaM targets such as the CaMKII inhibitor KN-62 (4 $\mu \mathrm{M})$, the PDE1 inhibitor MMPX (40 $\mu \mathrm{M})$, and the calcineurin inhibitor ascomycin $(1 \mu \mathrm{M})$. None of these showed significant effects on eEPSCs (Fig. 6D) or mEPSCs (Fig. 6E) except ascomycin, which slightly reduced the amplitudes of eEPSCs (Fig. 6D; Table 2). Ascomycin, however, did not affect mEPSC frequency (Fig. 6E), suggesting that it does not act in the pathway inhibited by W-7 and ML-9. Thus, we conclude that inhibition of MLCK, but not other CaM targets, results from inhibiting $\mathrm{CaM}$ in RB terminals.

\section{Inhibition of MLCK also inhibits presynaptic $\mathrm{Ca}$ currents and potentiates $\mathrm{Ca}^{2+}$-independent spontaneous release}

We repeated several experiments performed with $W$ 7 using ML-9 to confirm that the two agents exerted broadly similar effects. ML-9 inhibited LY-evoked EPSCs recorded in Alls (Fig. 7A1,A2) and Ca currents recorded in RBs (Fig. 7B1,B2). As well, ML-9 acted as W-7 did under the two experimental conditions in

Table 2: The effects of inhibitors on All eEPSC amplitude and mEPSC frequency

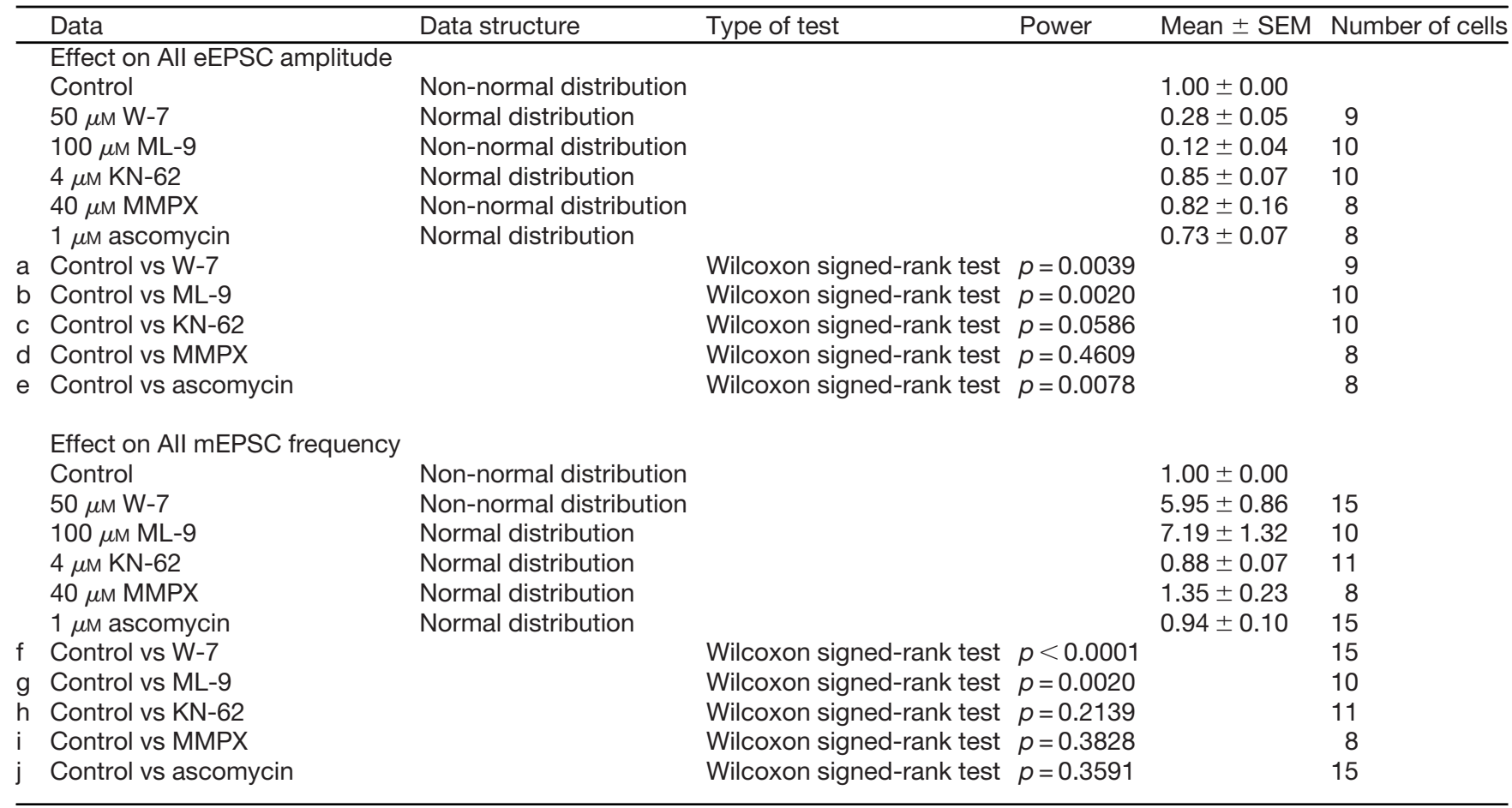


A1

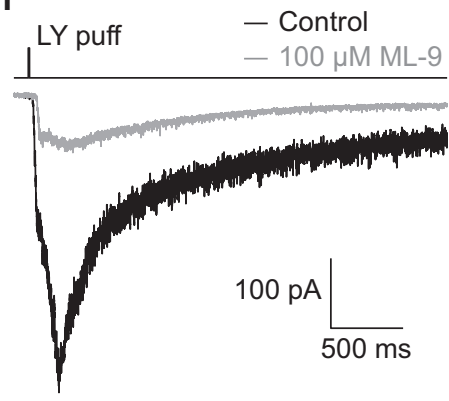

B1

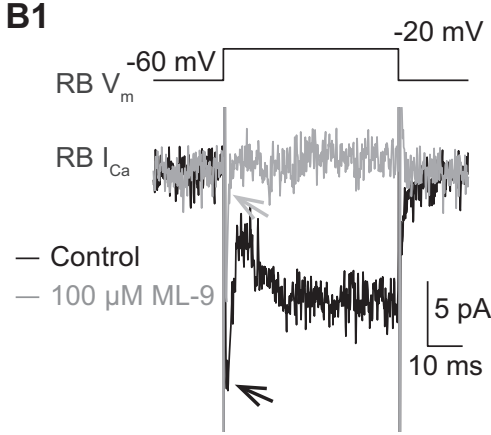

A2

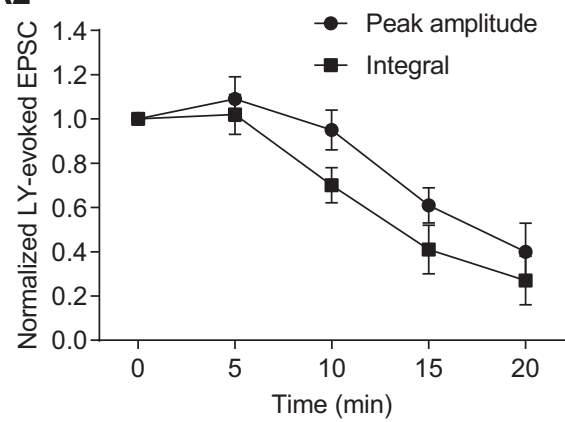

B2

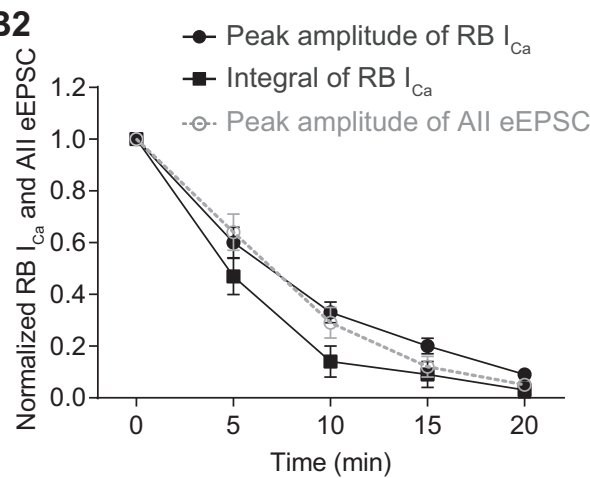

Figure 7. Inhibition of MLCK strongly reduces evoked release by suppressing calcium currents in RBs. A1, Average traces showing that EPSCs recorded in an All, evoked by puffing LY 341495 (LY), an mGluR6 antagonist, onto the dendrites of RBs located at the OPL, were strongly reduced by application of $100 \mu \mathrm{M}$ ML-9. V hold $=-80 \mathrm{mV}$. A2, LY-evoked EPSCs decreased over time with bath application of $100 \mu \mathrm{M}$ ML-9 $(n=5)$. The peak amplitudes and integrals of EPSCs were normalized to the amplitude and integral at time 0 , respectively, in each cell before averaging across cells. All the data were illustrated as mean \pm SEM. B1, Average traces showing that ML-9 $(100 \mu \mathrm{M})$ strongly suppressed the voltage step-generated calcium currents $\left(\mathrm{I}_{\mathrm{Ca}}\right)$ in an RB. B2, Statistics of the effects of $100 \mu \mathrm{M}$ ML-9 $(n=10)$ on the peak amplitude and integral of RB $I_{\text {Ca. }}$. The suppression of $I_{C a}$ recorded in RBs was closely related to the inhibition of eEPSCs recorded in Alls (adapted from Fig. 6A3, superimposed in gray). All the data were illustrated as mean \pm SEM.

which extracellular and intracellular $\left[\mathrm{Ca}^{2+}\right]$ were altered (compare Figs. 5 and 8; Table 3).

\section{Inhibition of CaM occludes the potentiating effect of MLCK inhibition on spontaneous release}

To determine whether W-7 and ML-9 exerted their effects via the same intracellular signaling pathway (i.e., the CaMMLCK pathway), we performed an occlusion experiment: following inhibition of CaM with W-7 (>20-min preincubation), we antagonized MLCK with ML-9. If inhibition of CaM reduces MLCK activity, then we expected the effect of ML-9 to be reduced in the presence of $\mathrm{W}-7$. Indeed, the experimental result is in line with this expectation.

Specifically, in the presence of $50 \mu \mathrm{M} \mathrm{W}-7$ (>20-min preincubation), application of $100 \mu \mathrm{M}$ ML-9 did not increase, but instead reduced, All mEPSC frequency (control 1 vs ML-9, 1.00 vs 0.12, $n=13, p=0.0002$; Fig. $9 A, C$ ). As a control for the prolonged recording period, we measured mEPSC frequencies over time in the absence of any drug application and noted that mEPSC frequency declined over time (control 2 vs no drug, 1.00 vs $0.41, n=8$, $p=0.0078$; Fig. 9B,C), although the decline was less pronounced than in the W-7 + ML-9 condition (ML-9 vs no drug, $p=0.0001$; Fig. $9 C$ ). DMSO alone did not have any additional effect on mEPSC frequency compared with the control condition (control 3 vs DMSO, 1.00 vs $0.45, n=7$, $p=0.0156$; DMSO vs no drug, $p=0.7337$; Fig. $9 C$ ). We conclude, then, that the CaM-MLCK pathway is involved in regulating spontaneous release from RBs.

\section{Discussion}

We monitored the dynamics of transmission at $\mathrm{RB} \rightarrow$ All synapses to examine the effects of modulating presynaptic CaM and its target proteins and made two major findings. One, we found that inhibition of CaM strongly reduced evoked release by suppressing presynaptic $\mathrm{Ca}$ currents while simultaneously potentiating both $\mathrm{Ca}^{2+}$-dependent and $\mathrm{Ca}^{2+}$-independent spontaneous release (Figs. 2-5). Two, the effect of inhibiting CaM seemed to be mediated by inhibition of MLCK but not other CaM downstream targets (including CaMKII, PDE1 and calcineurin; Figs. 6-9). Thus, CaM, via activation of MLCK, suppresses spontaneous release and promotes evoked release at retinal ribbon synapses.

\section{Pharmacological agents}

Concerns about the specificity of pharmacological agents are common and vex experimentalists. We 


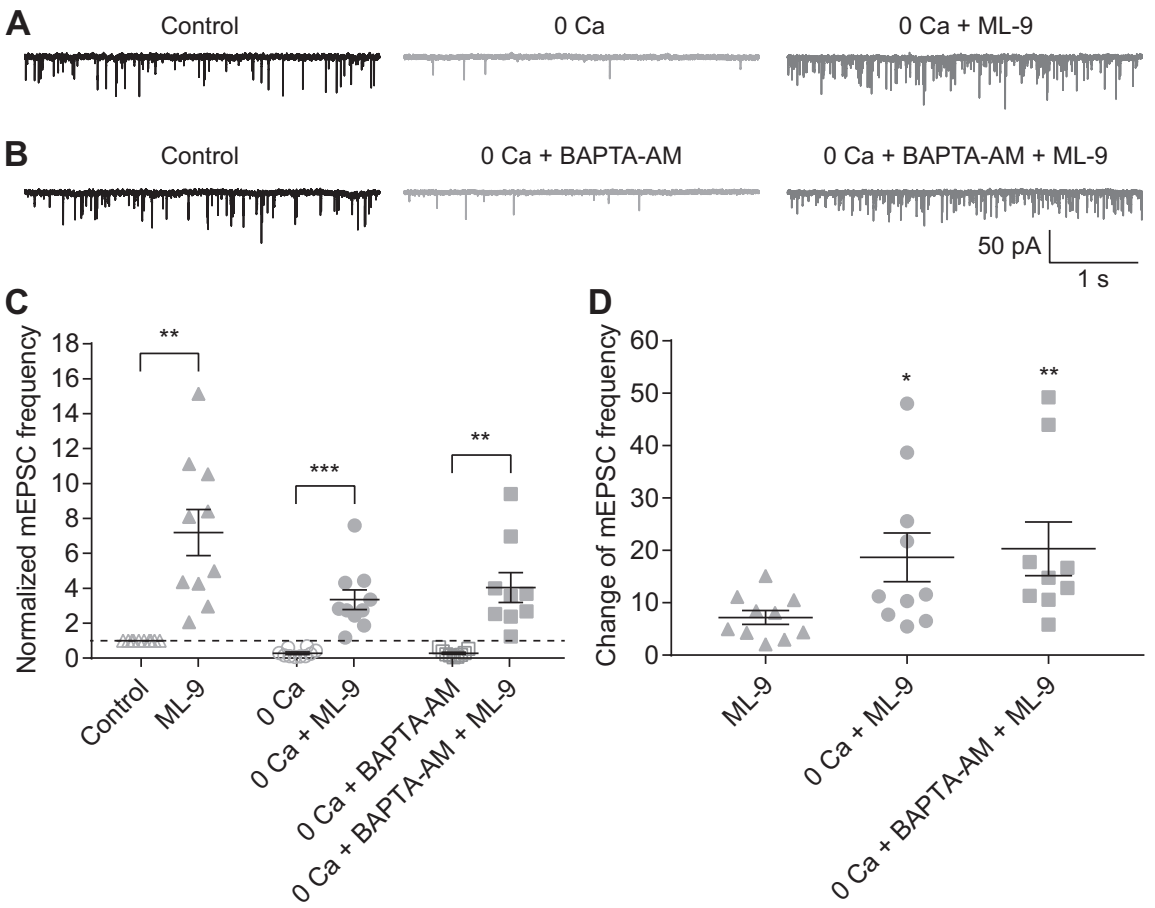

Figure 8. Both $\mathrm{Ca}^{2+}$-dependent and $\mathrm{Ca}^{2+}$-independent spontaneous release are enhanced, but to different extents, when MLCK is inhibited. $\boldsymbol{A}, \boldsymbol{B}$, Representative traces showing All mEPSCs under control, and different combinations of removal of extracellular calcium (0 Ca), $10 \mu \mathrm{m}$ BAPTA-AM and $100 \mu \mathrm{m}$ ML-9 conditions. $\boldsymbol{C}$, Summary data for All mEPSC frequency under two experimental conditions in $\boldsymbol{A}$ (empty and full circles) and $\boldsymbol{B}$ (empty and full squares). The data under control and ML-9 conditions (adapted from Fig. 6B1, empty and full triangles, respectively) were also presented for direct comparison. The frequencies were normalized to the frequency under control condition in each cell before averaging across cells. The data were also illustrated as mean \pm SEM. Wilcoxon signed-rank tests were used (control vs ML-9, $n=10, p=0.0020 ; 0 \mathrm{Ca}+$ BAPTA-AM vs $0 \mathrm{Ca}+$ BAPTA-AM + ML-9, $n=9, p=0.0039$ ) except for comparison of 0 Ca and 0 Ca + ML-9 data by paired Student's $t$ test $(n=10, p=0.0001)$; ${ }^{\star \star} p<0.01,{ }^{\star \star \star} p<0.001$. $\boldsymbol{D}$, Summary data for changes of All mEPSC frequency after bath application of $100 \mu \mathrm{M}$ ML-9 for $15 \mathrm{~min}$ under control and two experimental conditions. The change in each cell was calculated as the ratio of $\mathrm{mEPSC}$ frequencies before and $15 \mathrm{~min}$ after application of ML-9. The data were also illustrated as mean \pm SEM. Mann-Whitney tests were used (ML-9 vs $0 \mathrm{Ca}+\mathrm{ML}-9, p=0.0232 ; \mathrm{ML}-9$ vs $0 \mathrm{Ca}+\mathrm{BAPTA}-\mathrm{AM}+\mathrm{ML}-9, p=0.0030) ;{ }^{*} p<0.05,{ }^{* \star} p<0.01$.

Table 3: The effects of ML-9 on All mEPSC frequency under different conditions

\begin{tabular}{|c|c|c|c|c|c|}
\hline Data & Data structure & Type of test & Power & Mean \pm SEM & Number of cells \\
\hline Control & Non-normal distribution & & & $1.00 \pm 0.00$ & 10 \\
\hline $100 \mu \mathrm{M}$ ML-9 & Normal distribution & & & $7.19 \pm 1.32$ & 10 \\
\hline a Control vs ML-9 & & $\begin{array}{l}\text { Wilcoxon } \\
\text { signed-rank test }\end{array}$ & $p=0.0020$ & & \\
\hline $\begin{array}{l}0 \mathrm{Ca}^{2+} \\
\quad(\text { experimental condition } 1)\end{array}$ & Normal distribution & & & $0.28 \pm 0.07$ & 10 \\
\hline $0 \mathrm{Ca}^{2+}+\mathrm{ML}-9$ & Normal distribution & & & $3.35 \pm 0.57$ & 10 \\
\hline $\begin{array}{l}\text { (experimental condition 2) } \\
\text { (ea }{ }^{2+}+\text { BAPTA-AM }\end{array}$ & Normal distribution & paired $t$ test & $p=0.0001$ & $0.28 \pm 0.07$ & 9 \\
\hline $0 \mathrm{Ca}^{2+}+$ BAPTA-AM + ML-9 & Non-normal distribution & & & $4.04 \pm 0.85$ & 9 \\
\hline $\begin{array}{l}\text { c } 0 \mathrm{Ca}^{2+}+\text { BAPTA-AM vs } \\
\quad 0 \mathrm{Ca}^{2+}+\text { BAPTA-AM + ML-9 }\end{array}$ & & $\begin{array}{l}\text { Wilcoxon } \\
\text { signed-rank test }\end{array}$ & $p=0.0039$ & & \\
\hline \multicolumn{6}{|l|}{$\begin{array}{l}\text { Relative effect of ML-9 under different } \\
\text { conditions }\end{array}$} \\
\hline ML-9 effect under control condition & Normal distribution & & & $7.19 \pm 1.32$ & 10 \\
\hline ML-9 effect under experimental condition 1 & Non-normal distribution & & & $18.69 \pm 4.64$ & 10 \\
\hline ML-9 effect under experimental condition 2 & Non-normal distribution & & & $20.31 \pm 5.12$ & 9 \\
\hline $\begin{array}{l}\text { d ML-9 (experimental condition 1) vs ML-9 } \\
\text { (control condition) }\end{array}$ & & Mann-Whitney test & $p=0.0232$ & & \\
\hline $\begin{array}{l}\text { e ML-9 (experimental condition 2) vs ML-9 } \\
\text { (control condition) }\end{array}$ & & Mann-Whitney test & $p=0.0030$ & & \\
\hline
\end{tabular}

$0 \mathrm{Ca}^{2+}:$ remove extracellular $\mathrm{Ca}^{2+}$. 
A Control (with $50 \mu \mathrm{M} \mathrm{W}$-7)

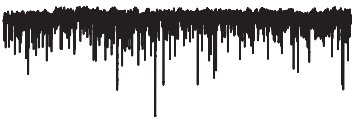

B

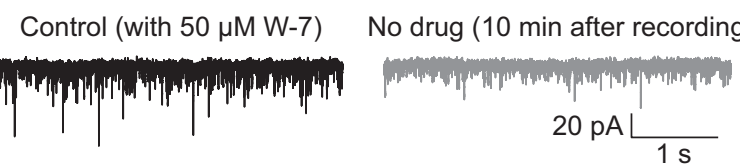

C

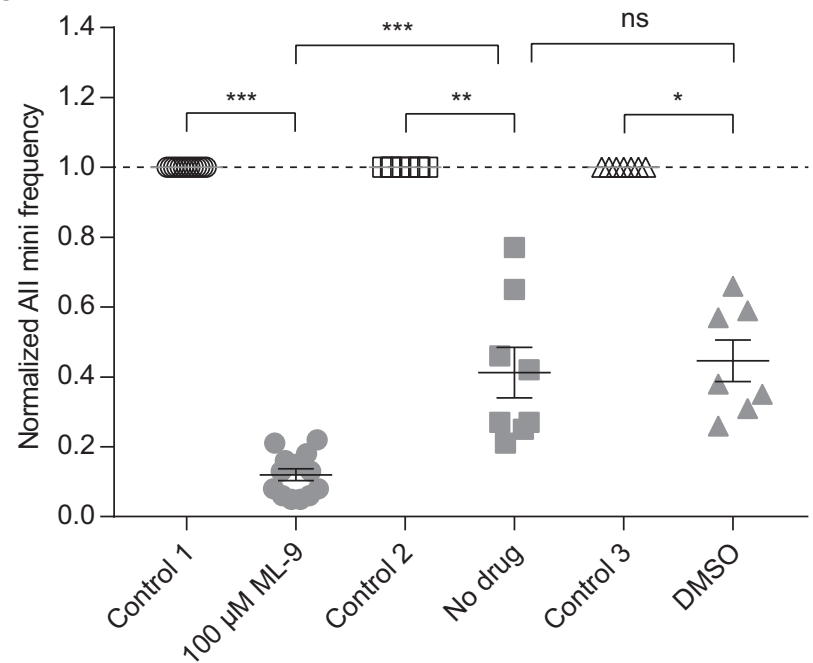

Figure 9. Inhibition of CaM occludes the effect of MLCK inhibition on spontaneous release. $\boldsymbol{A}$, Representative traces showing that, after preincubation with $50 \mu \mathrm{M} \mathrm{W}-7,100 \mu \mathrm{M} \mathrm{ML}-9$ did not increase, but instead reduced, All mEPSC frequency. $\boldsymbol{B}$, Representative traces showing that, after preincubation with $50 \mu \mathrm{M} \mathrm{W}-7$, All mEPSC frequency decreased significantly after 10-min recording. C, Summary data for All mEPSC frequency under three experimental conditions in $\boldsymbol{A}$ (empty and full circles), $\boldsymbol{B}$ (empty and full squares), and DMSO control (empty and full triangles). The frequencies were normalized to the frequency under control condition in each cell before averaging across cells. The data were also illustrated as mean \pm SEM. Wilcoxon signed-rank tests (control 1 vs ML-9, $n=13, p=0.0002$; control 2 vs no drug, $n=8, p=0.0078$; control 3 vs DMSO, $n=7, p=0.0156$ ) or unpaired Student's $t$ test (ML-9 vs no drug, $p=0.0001$; no drug vs DMSO, $p=0.7337$ ) were used for comparison; ${ }^{*} p<0.05,{ }^{* \star} p<0.01,{ }^{\star * *} p<0.001$; ns: not statistically significant.

made three observations that should assuage such concerns. One, our immunohistochemical analysis revealed extremely high expression of $\mathrm{CaM}$ in $\mathrm{RB}$ axon terminals. Even so, application of CaM antagonists such as W-7 might exert off-target effects. Therefore, we tested a structurally dissimilar CaM antagonist, CMZ (Gietzen et al., 1982), in our preparation and found that at concentrations of $50-100 \mu \mathrm{M}$, it too reduced evoked release, although to a lesser extent (Fig. $2 E$ ). We also tested the effects of CALP1, a CaM agonist (Villain et al., 2000). CALP1 reduced spontaneous release, especially after removal of extracellular $\mathrm{Ca}^{2+}$, whereas it had no effect on evoked release (Fig. 2E,F), which might be explained by the almost full activation of $\mathrm{CaM}$ by $\mathrm{Ca}^{2+}$ sufficient to saturate endogenous buffers (Mehta et al., 2014) under our experimental conditions. Three, inhibition of MLCK also bidirectionally regulated evoked and spontaneous release and the effect could be occluded by preinhibition of $\mathrm{CaM}$, which would in turn support the conclusion that neurotransmitter release at $\mathrm{RB} \rightarrow$ All synapse is modulated by CaM.

Although CaBP5 is expressed in mouse retinal RBs and is suggested to be involved in neurotransmitter release since it interacts with Munc18-1 and myosin VI (Haeseleer et al., 2000; Rieke et al., 2008; Sokal and Haeseleer, 2011), to our knowledge, there is no evidence showing that $\mathrm{W}-7$ could antagonize CaBP5. It has been shown that CaBP5 has only a relatively weak effect on inactivation of Ca currents when cotransfected with calcium channels in HEK293T cells (Rieke et al., 2008). In contrast, we found that $\mathrm{W}-7$ inhibited $\mathrm{RB} \mathrm{I}_{\mathrm{Ca}}$ strongly. This would indicate that, even if W-7 might inhibit CaBP5, it exerted its inhibitory effect on $\mathrm{RB} \mathrm{I}_{\mathrm{Ca}}$ by primarily targeting $\mathrm{CaM}$, rather than CaBP5.

\section{CaM and its downstream targets at ribbon synapses}

It has been proposed that CaMKII may be the downstream target of CaM in regulation of evoked release (Llinás et al., 1985; Pang et al., 2010). CaMKII has been found located close to synaptic ribbons (Uthaiah and Hudspeth, 2010; Kantardzhieva et al., 2012), and it has been shown to phosphorylate syntaxin $3 \mathrm{~B}$, the retinal isoform of syntaxin and an essential component of the core SNARE complex mediating vesicle fusion (Liu et al., 2014). We were surprised, then, that the CaMKII inhibitor KN-62 only had a small (not significant) effect on either evoked or spontaneous release at $\mathrm{RB} \rightarrow$ All synapses. In contrast, the MLCK inhibitor ML-9 exerted strong effects on both two forms of release.

MLCK has been suggested to be involved in regulation of neurotransmitter release, with opposing effects observed at different synapses (Mochida et al., 1994; Mochida, 1995; Ryan, 1999; Polo-Parada et al., 2005; Srinivasan et al., 2008), although there is a study arguing that MLCK is not a regulator for synaptic vesicle trafficking in hippocampal neurons (Tokuoka and Goda, 2006). In addition, MLCK accelerates vesicle endocytosis at the calyx of Held and hippocampal synapses (Yue and Xu, 2014; Li et al., 2016) and enhances ribbon replenishment in cone photoreceptors (Van Hook et al., 2014). Our findings support the role that MLCK plays in regulating neurotransmitter release. We could imagine that inhibition of MLCK slowed down the replenishment of vesicle pools and reduced subsequent evoked release by making the readily-releasable pool (RRP) of vesicles smaller. Potentially, reducing the RRP size could shunt vesicles into a spontaneously-releasing pool.

\section{CaM regulates evoked and spontaneous release differentially}

Recent studies have showed selective molecular regulation of evoked and spontaneous release. Proteins such 
as RIM1 and RBPs, modulate evoked, but not spontaneous, release (Calakos et al., 2004; Acuna et al., 2015; Robinson et al., 2019), whereas proteins such as Vti1a, VAMP7, Doc2, and copine-6, modulate spontaneous, but not evoked, release (Groffen et al., 2010; Pang et al., 2011; Ramirez et al., 2012; Bal et al., 2013; Liu et al., 2018). Despite this, it is clear that evoked and spontaneous release do not use completely nonoverlapping molecular machinery: both are mediated by the canonical SNARE complex including syntaxin and SNAP-25 (Südhof, 2012). Additionally, synaptotagmin-1 and complexins have been shown to control both evoked and spontaneous release (Maximov and Südhof, 2005; Huntwork and Littleton, 2007; Xu et al., 2009; Yang et al., 2013; Bai et al., 2016; Grassmeyer et al., 2019; López-Murcia et al., 2019). Indeed, knock-out of complexin three abolishes fast, synchronous release while enhancing spontaneous release at $\mathrm{RB} \rightarrow$ All synapses (Mortensen et al., 2016). Our present study thus likely would add CaM as well as MLCK into the family of dual regulators of evoked and spontaneous release.

Inhibition of CaM by $\mathrm{W}-7$ reduced evoked release by suppressing $\mathrm{Ca}^{2+}$ influx into RB axon terminals (Fig. 4). CaM can directly bind several types of VGCCs and thereby regulate their activity (Ben-Johny and Yue, 2014). Generally, CaM is thought to mediate $\mathrm{Ca}^{2+}$-dependent inactivation (CDI) of $\mathrm{Ca}$ channels (Ben-Johny and Yue, 2014; Pangrsic et al., 2018). Ca currents in RB terminals, however, show little CDI (Singer and Diamond, 2003; Jarsky et al., 2011; Dolphin and Lee, 2020), and here W-7 (i.e., inhibiting $\mathrm{CaM}$ ) inhibited rather than potentiated $\mathrm{Ca}$ currents. Thus, CaM likely does not bind to $\mathrm{Ca}$ channels in RB terminals directly.

It has been reported that W-7 can inhibit VGCCs in some non-neuronal systems such as ciliary membrane of Paramecium and smooth muscle from rat vas deferens (Hennessey and Kung, 1984; Nakazawa et al., 1993). CMZ inhibits VGCCs in different smooth muscle cells (Klöckner and Isenberg, 1987; Nakazawa et al., 1993; Sunagawa et al., 1999), but it has no effect on Ca currents in Paramecium (Ehrlich et al., 1988). The inhibitory effects of W-7 and CMZ on VGCCs are suggested to be CaM-independent and likely because of direct actions of these drugs on VGCCs, based on the limited evidence that exogenous CaM has no effect on VGCCs and that CaMKII antagonists, when applied either extracellularly or intracellularly, do not block the effect of CMZ on VGCCs (Klöckner and Isenberg, 1987; Ehrlich et al., 1988; Sunagawa et al., 1999).

Similar results have also been observed in our study: activation of CaM by CALP1 did not enhance evoked release, and neither CaMKII nor PDE1 seemed to be involved in regulating neurotransmitter release from RBs. Note, however, that W-7 and CMZ likely have distinct effects on different CaM-dependent pathways. For example, $\mathrm{CMZ}$, at the concentration of $1 \mu \mathrm{M}$, dramatically inhibits the activity of CaM-dependent PDE, while W-7, even at the concentration as high as $100 \mu \mathrm{m}$, only has a very small effect (Ehrlich et al., 1988). By contrast, it may be possible that $\mathrm{W}-7$ has a stronger effect on other downstream targets of CaM, such as MLCK, than CMZ. Indeed, we found that W-7 inhibited evoked release from RBs more strongly than CMZ, and MLCK was likely the mediator of the effects observed. It has been shown that ML-9 (and also its structural analog, ML-7) inhibits VGCCs in hippocampal neurons, and this effect may be independent of MLCK since it is not mimicked by wortmannin, a relatively non-specific MLCK inhibitor (Tokuoka and Goda, 2006). We could not exclude the possibility that both W-7 and ML-9 inhibit VGCCs directly. But it is unlikely to be true since ML-9 not only closely mimicked the effects of W-7 on VGCCs and evoked release but also on $\mathrm{Ca}^{2+}$-independent spontaneous release (Figs. 2, 5, 6, 8), which is not related to VGCCs. Further, preincubation of W-7 completely occluded the potentiating effect of ML9 on spontaneous release (Fig. 9), indicating that these two drugs exerted their effects via the same (CaM-MLCK) pathway.

Evidence for direct interactions between MLCK and $\mathrm{Ca}$ channels in RB terminals is not apparent in the literature, and therefore it will be interesting to explore how MLCK controls the activity of $\mathrm{Ca}$ channels and $\mathrm{Ca}^{2+}$-dependent exocytosis in the future. But generally, our present observations support the notion that CaM promotes evoked release, which is consistent with other studies (Chamberlain et al., 1995; Chen et al., 1999; Junge et al., 2004; Pang et al., 2010).

Unique mechanisms of spontaneous neurotransmitter release have received significant attention recently (Kavalali, 2015). Spontaneous release is largely dependent on $\mathrm{Ca}^{2+}$ influx through VGCCs or $\mathrm{Ca}^{2+}$ efflux from internal stores (Kaeser and Regehr, 2014; Schneggenburger and Rosenmund, 2015; Williams and Smith, 2017). Indeed, we observed that spontaneous release was reduced by $\sim 70 \%$ (Figs. 5, 8) when the extracellular $\mathrm{Ca}^{2+}$ was removed and the intracellular $\mathrm{Ca}^{2+}$ was buffered by the membrane permeable $\mathrm{Ca}^{2+}$ chelator BAPTA-AM. Our observations, however, indicate that there is a $\mathrm{Ca}^{2+}$-independent component of spontaneous release that is poorly understood. Given that spontaneous energy fluctuations that overcome the energy barrier for vesicle fusion can trigger spontaneous exocytosis (Schneggenburger and Rosenmund, 2015), we believe it possible that inhibition of CaM or MLCK somehow reduces the energy barrier to exocytosis, much as $\mathrm{Ca}^{2+}$ binding to synaptotagmin does.

\section{References}

Abrahamsson T, Chou CYC, Li SY, Mancino A, Costa RP, Brock JA, Nuro E, Buchanan KA, Elgar D, Blackman AV, Tudor-Jones A, Oyrer J, Farmer WT, Murai KK, Sjöström PJ (2017) Differential regulation of evoked and spontaneous release by presynaptic NMDA receptors. Neuron 96:839-855.

Acuna C, Liu X, Gonzalez A, Südhof TC (2015) RIM-BPs mediate tight coupling of action potentials to $\mathrm{Ca}(2+)$-triggered neurotransmitter release. Neuron 87:1234-1247.

Andreae LC, Burrone J (2018) The role of spontaneous neurotransmission in synapse and circuit development. J Neurosci Res 96:354-359.

Bai H, Xue R, Bao H, Zhang L, Yethiraj A, Cui Q, Chapman ER (2016) Different states of synaptotagmin regulate evoked versus spontaneous release. Nat Commun 7:10971.

Bal M, Leitz J, Reese AL, Ramirez DM, Durakoglugil M, Herz J, Monteggia LM, Kavalali ET (2013) Reelin mobilizes a VAMP7-dependent synaptic vesicle pool and selectively augments spontaneous neurotransmission. Neuron 80:934-946. 
Ben-Johny M, Yue DT (2014) Calmodulin regulation (calmodulation) of voltage-gated calcium channels. J Gen Physiol 143:679-692.

Calakos N, Schoch S, Südhof TC, Malenka RC (2004) Multiple roles for the active zone protein RIM1alpha in late stages of neurotransmitter release. Neuron 42:889-896.

Chamberlain LH, Roth D, Morgan A, Burgoyne RD (1995) Distinct effects of alpha-SNAP, 14-3-3 proteins, and calmodulin on priming and triggering of regulated exocytosis. J Cell Biol 130:1063-1070.

Chanaday NL, Kavalali ET (2018) Presynaptic origins of distinct modes of neurotransmitter release. Curr Opin Neurobiol 51:119126.

Chen M, Van Hook MJ, Zenisek D, Thoreson WB (2013) Properties of ribbon and non-ribbon release from rod photoreceptors revealed by visualizing individual synaptic vesicles. J Neurosci 33:20712086

Chen YA, Duvvuri V, Schulman H, Scheller RH (1999) Calmodulin and protein kinase $\mathrm{C}$ increase $\mathrm{Ca}(2+)$-stimulated secretion by modulating membrane-attached exocytic machinery. J Biol Chem 274:26469-26476.

Cho S, von Gersdorff H (2012) Ca(2+) influx and neurotransmitter release at ribbon synapses. Cell Calcium 52:208-216.

Dolphin AC, Lee A (2020) Presynaptic calcium channels: specialized control of synaptic neurotransmitter release. Nat Rev Neurosci 21:213-229.

Ehrlich BE, Jacobson AR, Hinrichsen R, Sayre LM, Forte MA (1988) Paramecium calcium channels are blocked by a family of calmodulin antagonists. Proc Natl Acad Sci USA 85:5718-5722.

Fatt P, Katz B (1950) Some observations on biological noise. Nature 166:597-598.

Fatt P, Katz B (1952) Spontaneous subthreshold activity at motor nerve endings. J Physiol 117:109-128.

Gietzen K, Sadorf I, Bader H (1982) A model for the regulation of the calmodulin-dependent enzymes erythrocyte Ca2+-transport ATPase and brain phosphodiesterase by activators and inhibitors. Biochem J 207:541-548.

Grassmeyer JJ, Cahill AL, Hays CL, Barta C, Quadros RM, Gurumurthy $\mathrm{CB}$, Thoreson WB $(2019) \mathrm{Ca}(2+)$ sensor synaptotagmin-1 mediates exocytosis in mammalian photoreceptors. Elife 8: e45946.

Groemer TW, Klingauf J (2007) Synaptic vesicles recycling spontaneously and during activity belong to the same vesicle pool. Nat Neurosci 10:145-147.

Groffen AJ, Martens S, Díez Arazola R, Cornelisse LN, Lozovaya N, de Jong AP, Goriounova NA, Habets RL, Takai Y, Borst JG, Brose $\mathrm{N}$, McMahon HT, Verhage M (2010) Doc2b is a high-affinity Ca2+ sensor for spontaneous neurotransmitter release. Science 327:1614-1618.

Haeseleer F, Sokal I, Verlinde CL, Erdjument-Bromage H, Tempst P, Pronin AN, Benovic JL, Fariss RN, Palczewski K (2000) Five members of a novel $\mathrm{Ca}(2+)$-binding protein (CABP) subfamily with similarity to calmodulin. J Biol Chem 275:1247-1260.

Hennessey TM, Kung C (1984) An anticalmodulin drug, W-7, inhibits the voltage-dependent calcium current in Paramecium caudatum. J Exp Biol 110:169-181.

Hoeflich KP, Ikura M (2002) Calmodulin in action: diversity in target recognition and activation mechanisms. Cell 108:739-742.

Hua Y, Sinha R, Martineau M, Kahms M, Klingauf J (2010) A common origin of synaptic vesicles undergoing evoked and spontaneous fusion. Nat Neurosci 13:1451-1453.

Huntwork S, Littleton JT (2007) A complexin fusion clamp regulates spontaneous neurotransmitter release and synaptic growth. Nat Neurosci 10:1235-1237.

Ivanova E, Hwang GS, Pan ZH (2010) Characterization of transgenic mouse lines expressing Cre recombinase in the retina. Neuroscience 165:233-243.

Jarsky T, Cembrowski M, Logan SM, Kath WL, Riecke H, Demb JB, Singer JH (2011) A synaptic mechanism for retinal adaptation to luminance and contrast. J Neurosci 31:11003-11015.

Junge HJ, Rhee JS, Jahn O, Varoqueaux F, Spiess J, Waxham MN, Rosenmund C, Brose N (2004) Calmodulin and Munc13 form a
$\mathrm{Ca} 2+$ sensor/effector complex that controls short-term synaptic plasticity. Cell 118:389-401.

Kaeser PS, Regehr WG (2014) Molecular mechanisms for synchronous, asynchronous, and spontaneous neurotransmitter release. Annu Rev Physiol 76:333-363.

Kantardzhieva A, Peppi M, Lane WS, Sewell WF (2012) Protein composition of immunoprecipitated synaptic ribbons. J Proteome Res 11:1163-1174.

Kavalali ET (2015) The mechanisms and functions of spontaneous neurotransmitter release. Nat Rev Neurosci 16:5-16.

Klöckner U, Isenberg G (1987) Calmodulin antagonists depress calcium and potassium currents in ventricular and vascular myocytes. Am J Physiol 253:H1601-H1611.

Li L, Wu X, Yue HY, Zhu YC, Xu J (2016) Myosin light chain kinase facilitates endocytosis of synaptic vesicles at hippocampal boutons. J Neurochem 138:60-73.

Liu P, Khvotchev M, Li YC, Chanaday NL, Kavalali ET (2018) Copine6 binds to SNAREs and selectively suppresses spontaneous neurotransmission. J Neurosci 38:5888-5899.

Liu XQ, Heidelberger R, Janz R (2014) Phosphorylation of syntaxin 3B by CaMKII regulates the formation of t-SNARE complexes. Mol Cell Neurosci 60:53-62.

Llinás R, McGuinness TL, Leonard CS, Sugimori M, Greengard P (1985) Intraterminal injection of synapsin I or calcium/calmodulindependent protein kinase II alters neurotransmitter release at the squid giant synapse. Proc Natl Acad Sci USA 82:3035-3039.

López-Murcia FJ, Reim K, Jahn O, Taschenberger H, Brose N (2019) Acute complexin knockout abates spontaneous and evoked transmitter release. Cell Rep 26:2521-2530.

Madisen L, Mao T, Koch H, Zhuo JM, Berenyi A, Fujisawa S, Hsu YWA, Garcia AJ, Gu X, Zanella S, Kidney J, Gu H, Mao Y, Hooks BM, Boyden ES, Buzsáki G, Ramirez JM, Jones AR, Svoboda K, Han X, et al. (2012) A toolbox of Cre-dependent optogenetic transgenic mice for light-induced activation and silencing. Nat Neurosci 15:793-802.

Matthews G, Fuchs P (2010) The diverse roles of ribbon synapses in sensory neurotransmission. Nat Rev Neurosci 11:812-822.

Maxeiner S, Luo F, Tan A, Schmitz F, Südhof TC (2016) How to make a synaptic ribbon: RIBEYE deletion abolishes ribbons in retinal synapses and disrupts neurotransmitter release. EMBO J 35:1098-1114.

Maximov A, Südhof TC (2005) Autonomous function of synaptotagmin 1 in triggering synchronous release independent of asynchronous release. Neuron 48:547-554.

Mehta B, Snellman J, Chen S, Li W, Zenisek D (2013) Synaptic ribbons influence the size and frequency of miniature-like evoked postsynaptic currents. Neuron 77:516-527.

Mehta B, Ke JB, Zhang L, Baden AD, Markowitz AL, Nayak S, Briggman KL, Zenisek D, Singer JH (2014) Global Ca2 + signaling drives ribbon-independent synaptic transmission at rod bipolar cell synapses. J Neurosci 34:6233-6244.

Midorikawa M, Tsukamoto Y, Berglund K, Ishii M, Tachibana M (2007) Different roles of ribbon-associated and ribbon-free active zones in retinal bipolar cells. Nat Neurosci 10:1268-1276.

Mochida S (1995) Role of myosin in neurotransmitter release: functional studies at synapses formed in culture. J Physiol Paris 89:8394.

Mochida S, Kobayashi H, Matsuda Y, Yuda Y, Muramoto K, Nonomura $Y$ (1994) Myosin II is involved in transmitter release at synapses formed between rat sympathetic neurons in culture. Neuron 13:1131-1142.

Mortensen LS, Park SJH, Ke JB, Cooper BH, Zhang L, Imig C, Löwel S, Reim K, Brose N, Demb JB, Rhee JS, Singer JH (2016) Complexin 3 increases the fidelity of signaling in a retinal circuit by regulating exocytosis at ribbon synapses. Cell Rep 15:2239-2250.

Nakazawa K, Higo K, Abe K, Tanaka Y, Saito H, Matsuki N (1993) Blockade by calmodulin inhibitors of $\mathrm{Ca} 2+$ channels in smooth muscle from rat vas deferens. Br J Pharmacol 109:137-141. 
Pang ZP, Cao P, Xu W, Südhof TC (2010) Calmodulin controls synaptic strength via presynaptic activation of calmodulin kinase II. J Neurosci 30:4132-4142.

Pang ZP, Bacaj T, Yang X, Zhou P, Xu W, Südhof TC (2011) Doc2 supports spontaneous synaptic transmission by a $\mathrm{Ca}(2+)$-independent mechanism. Neuron 70:244-251.

Pangrsic T, Singer JH, Koschak A (2018) Voltage-gated calcium channels: key players in sensory coding in the retina and the inner ear. Physiol Rev 98:2063-2096.

Park SJH, Pottackal J, Ke JB, Jun NY, Rahmani P, Kim IJ, Singer JH, Demb JB (2018) Convergence and divergence of CRH amacrine cells in mouse retinal circuitry. J Neurosci 38:3753-3766.

Park SJH, Lieberman EE, Ke JB, Rho N, Ghorbani P, Rahmani P, Jun NY, Lee HL, Kim IJ, Briggman KL, Demb JB, Singer JH (2020) Connectomic analysis reveals an interneuron with an integral role in the retinal circuit for night vision. Elife 9:e56077.

Pochet R, Pasteels B, Seto-Ohshima A, Bastianelli E, Kitajima S, Van Eldik LJ (1991) Calmodulin and calbindin localization in retina from six vertebrate species. J Comp Neurol 314:750-762.

Polo-Parada L, Plattner F, Bose C, Landmesser LT (2005) NCAM 180 acting via a conserved C-terminal domain and MLCK is essential for effective transmission with repetitive stimulation. Neuron 46:917-931.

Ramirez DM, Khvotchev M, Trauterman B, Kavalali ET (2012) Vti1a identifies a vesicle pool that preferentially recycles at rest and maintains spontaneous neurotransmission. Neuron 73:121-134.

Rieke F, Lee A, Haeseleer F (2008) Characterization of Ca2 +-binding protein 5 knockout mouse retina. Invest Ophthalmol Vis Sci 49:5126-5135.

Robinson BG, Cai X, Wang J, Bunzow JR, Williams JT, Kaeser PS (2019) RIM is essential for stimulated but not spontaneous somatodendritic dopamine release in the midbrain. Elife 8:e47972.

Ryan TA (1999) Inhibitors of myosin light chain kinase block synaptic vesicle pool mobilization during action potential firing. J Neurosci 19:1317-1323.

Schneggenburger R, Rosenmund C (2015) Molecular mechanisms governing $\mathrm{Ca}(2+)$ regulation of evoked and spontaneous release. Nat Neurosci 18:935-941.

Schneider CA, Rasband WS, Eliceiri KW (2012) NIH Image to ImageJ: 25 years of image analysis. Nat Methods 9:671-675.

Singer JH (2007) Multivesicular release and saturation of glutamatergic signalling at retinal ribbon synapses. J Physiol 580:23-29.

Singer JH, Diamond JS (2003) Sustained Ca2 + entry elicits transient postsynaptic currents at a retinal ribbon synapse. J Neurosci 23:10923-10933.

Singer JH, Lassová L, Vardi N, Diamond JS (2004) Coordinated multivesicular release at a mammalian ribbon synapse. Nat Neurosci 7:826-833.

Singer JH, Glowatzki E, Moser T, Strowbridge BW, Bhandawat V, Sampath AP (2009) Functional properties of synaptic transmission in primary sense organs. J Neurosci 29:12802-12806.

Sokal I, Haeseleer F (2011) Insight into the role of Ca2 +-binding protein 5 in vesicle exocytosis. Invest Ophthalmol Vis Sci 52:91319141.
Srinivasan G, Kim JH, von Gersdorff H (2008) The pool of fast releasing vesicles is augmented by myosin light chain kinase inhibition at the calyx of Held synapse. J Neurophysiol 99:1810-1824.

Südhof TC (2012) The presynaptic active zone. Neuron 75:11-25.

Sunagawa M, Yokoshiki H, Seki T, Nakamura M, Laber P, Sperelakis N (1999) Direct block of Ca2 + channels by calmidazolium in cultured vascular smooth muscle cells. J Cardiovasc Pharmacol 34:488-496.

Tarasova EO, Gaydukov AE, Balezina OP (2018) Calcineurin and its role in synaptic transmission. Biochemistry (Mosc.) 83:674-689.

Tokuoka H, Goda Y (2006) Myosin light chain kinase is not a regulator of synaptic vesicle trafficking during repetitive exocytosis in cultured hippocampal neurons. J Neurosci 26:11606-11614.

Uthaiah RC, Hudspeth AJ (2010) Molecular anatomy of the hair cell's ribbon synapse. J Neurosci 30:12387-12399.

Van Hook MJ, Parmelee CM, Chen M, Cork KM, Curto C, Thoreson WB (2014) Calmodulin enhances ribbon replenishment and shapes filtering of synaptic transmission by cone photoreceptors. J Gen Physiol 144:357-378.

Veruki ML, Hartveit E (2009) Meclofenamic acid blocks electrical synapses of retinal All amacrine and on-cone bipolar cells. J Neurophysiol 101:2339-2347.

Villain M, Jackson PL, Manion MK, Dong WJ, Su Z, Fassina G, Johnson TM, Sakai TT, Krishna NR, Blalock JE (2000) De novo design of peptides targeted to the EF hands of calmodulin. J Biol Chem 275:2676-2685.

Wilhelm BG, Groemer TW, Rizzoli SO (2010) The same synaptic vesicles drive active and spontaneous release. Nat Neurosci 13:1454-1456.

Williams CL, Smith SM (2017) Calcium dependence of spontaneous neurotransmitter release. J Neurosci Res 96:335-347.

Xu J, Pang ZP, Shin OH, Südhof TC (2009) Synaptotagmin-1 functions as a $\mathrm{Ca} 2+$ sensor for spontaneous release. Nat Neurosci 12:759-766.

Yang X, Cao P, Südhof TC (2013) Deconstructing complexin function in activating and clamping Ca2+-triggered exocytosis by comparing knockout and knockdown phenotypes. Proc Natl Acad Sci USA 110:20777-20782.

Yue HY, Xu J (2014) Myosin light chain kinase accelerates vesicle endocytosis at the calyx of Held synapse. J Neurosci 34:295-304.

Zariwala HA, Borghuis BG, Hoogland TM, Madisen L, Tian L, De Zeeuw Cl, Zeng H, Looger LL, Svoboda K, Chen TW (2012) A Credependent GCaMP3 reporter mouse for neuronal imaging in vivo. J Neurosci 32:3131-3141.

Zenisek D (2008) Vesicle association and exocytosis at ribbon and extraribbon sites in retinal bipolar cell presynaptic terminals. Proc Natl Acad Sci USA 105:4922-4927.

Zhang XM, Chen BY, Ng AH, Tanner JA, Tay D, So KF, Rachel RA, Copeland NG, Jenkins NA, Huang JD (2005) Transgenic mice expressing Cre-recombinase specifically in retinal rod bipolar neurons. Invest Ophthalmol Vis Sci 46:3515-3520. 